\title{
Anion exchange resin and slow precipitation preclude the need for pretreatments in silver phosphate preparation for oxygen isotope analysis of bioapatites
}

\author{
Sarah Pederzani ${ }^{\mathrm{a}, \mathrm{b}, *}$, Christophe Snoeck ${ }^{\mathrm{c}, \mathrm{d}}$, Ulrike Wacker ${ }^{\mathrm{a}}$, Kate Britton ${ }^{\mathrm{a}, \mathrm{b}}$ \\ ${ }^{a}$ Department of Human Evolution, Max-Planck-Institute of Evolutionary Anthropology, Deutscher Platz 6, 04103, Leipzig, Germany \\ ${ }^{b}$ Department of Archaeology, School of Geosciences, University of Aberdeen, Elphinstone Road, Aberdeen, AB24 3UF, United Kingdom \\ ${ }^{c}$ Analytical, Environmental \& Geo-Chemistry, Dept. of Chemistry, Vrije Universiteit Brussel, AMGC-WE-VUB, Pleinlaan 2, 1050, \\ Brussels, Belgium \\ ${ }^{d}$ G-Time Laboratory, Université Libre de Bruxelles, CP 160/02, 50, Avenue F. D. Roosevelt, B-1050, Brussels, Belgium
}

\section{Abstract}

Preventing the inclusion of oxygen bearing compounds from the organic fraction of skeletal tissues is often considered key to obtaining faithful $\delta^{18} \mathrm{O}$ measurements of the mineral fraction, which are widely used across the archaeological, forensic and geochemical sciences. Here we re-explore the contentious issue of organic removal pretreatments by establishing how different silver phosphate preparation methods perform in producing pure silver phosphates with a faithful biogenic isotopic signal. We then compare this baseline performance to a pretreatment based approach. Our results show that anion exchange purification combined with slow precipitation of silver phosphate consistently produces silver phosphates of high purity without prior pretreatment. Rapid precipitation protocols without additional purification, while effective and time-efficient for low organic samples such as enamel, suffer from the inclusion of substantial amount of organic matter in silver phosphates from bone or dentine samples. However, despite substantial organic contamination in such samples, $\delta^{18} \mathrm{O}$ values do not necessarily show substantial shifts. Further study is needed to clarify the reason for this, but for now the use of an anion exchange based protocol represents the most cautious approach to processing bone and dentine samples and we recommend its use for such samples. Confirming previous work we find $\mathrm{H}_{2} \mathrm{O}_{2}$ pretreatment to be only partially effective at removing higher amounts of organic matter. Both $\mathrm{H}_{2} \mathrm{O}_{2}$ and $\mathrm{NaOCl}$ pretreatments show unpredictable side effects on $\delta^{18} \mathrm{O}$ values of both bones and inorganic samples. We additionally find no indication that the presence of organic material hinders the dissolution of bioapatite samples.

Keywords: bioapatite phosphate, bone, enamel, palaeoclimate reconstruction, mobility, $\delta^{18} \mathrm{O}$

\footnotetext{
*Corresponding Author

Email address: sarah_pederzani@eva.mpg.de (Sarah Pederzani)
} 


\section{Introduction}

Stable oxygen isotope analysis of skeletal remains is one of the most widely applied stable isotope techniques to study past societies and environments. Applications range over a large variety of topics and fields including palaeoclimate reconstruction, mobility and life history of humans and other animals, palaeoecology, trade, or even cultural practices such as breastfeeding or culinary preparation (see review in Pederzani and Britton, 2019). The vast majority of oxygen isotope studies of skeletal remains are based on $\delta^{18} \mathrm{O}$ measurements of bioapatite carbonate or bioapatite phosphate (although see Tuross et al., 2008 for $\delta^{18} \mathrm{O}$ of collagen), and obtaining a faithful measurement of the original biological isotopic composition of bioapatite is key. While bioapatite carbonate is more commonly analysed, analysis of the phosphate group is generally preferred for older materials and bone bioapatite, due to its stronger resistance to diagenetic change (Iacumin et al., 1996; Lécuyer et al., 1999; Zazzo et al., 2004; Lee-Thorp and Sealy, 2008). Additionally, many key relationships between climatic variables and bioapatite $\delta^{18} \mathrm{O}$ values were established using $\delta^{18} \mathrm{O}$ values of bioapatite phosphate $\left(\delta^{18} \mathrm{O}_{\text {phos }}\right)$ (Longinelli and Nuti, 1973; Longinelli, 1984; Luz et al., 1984; Luz et al., 1990; Bryant et al., 1994; Cormie et al., 1994), leading to a predominance of analyses of the phosphate group in palaeoclimate work.

Oxygen isotope analyses of skeletal remains are most commonly conducted on dental enamel, due to its low organic content and high resistance to post-depositional alteration. Nonetheless there is continuing interest in oxygen isotope analysis of bone material for several reasons. Bone fragments are often much more abundant in archaeological and palaeontological assemblages than complete teeth, and their analysis can enable larger scale studies and extend diachronic and spatial coverage. Additionally, analyses of bone material allow the study of animal groups that do not possess teeth such as birds or turtles (e.g. Amiot et al., 2017; Matson and Fox, 2008). Bone bioapatite also provides an oxygen isotopic signal that is representative of the years before death, making it valuable for studies of lifetime mobility or adult behaviour in humans or other animals, as opposed to short-term seasonal insights offered through the analysis of teeth. However, analyses of bone (and to a lesser extent dental) bioapatite phosphate suffer from analytical challenges related to the presence of organic material in the tissue. Eliminating interference from organic matter for obtaining 'pristine' $\delta^{18} \mathrm{O}_{\text {phos }}$ from both enamel and bone has been widely recognized as a key issue and has been discussed in a number of works (e.g. Crowson et al., 1991; O'Neil et al., 1994; Stephan, 2000; Wiedemann-Bidlack et al., 2008; Grimes and Pellegrini, 2013; Shabaga et al., 2018), while the separation from the carbonate group is thought to be efficiently achieved with current preparation methods. However, there is a lack of consensus on how a pristine bioapatite $\delta^{18} \mathrm{O}$ signal can be achieved, particularly in bioapatite phosphate. A number of chemical pretreatments that remove organic material prior to routine sample preparation have been proposed (e.g. O’Neil et al., 1994; Quade et al., 1992; Stephan, 2000) (see section 1.2), but opinions differ on which pretreatment is to be preferred, or even whether this is necessary at all. Pretreatment studies often face challenges with small sample size and results that may be contradictory and difficult to interpret, causing disagreements on sample pretreatment methodology. At the same time, several routine sample preparation methods are currently in 
use (see section 1.1), and how each method performs in preventing contamination of silver phosphate with organic material has not been explored in a quantifiable way (see Stephan, 2000 for comparisons in terms of crystal colour).

Contamination with oxygen bearing groups from the organic fraction has the potential to substantially alter $\delta^{18} \mathrm{O}$ measurements of bioapatite, because the oxygen isotopic composition of the organic proteinaceous fraction of skeletal tissues differs strongly from that of the mineral bioapatite fraction. This is due to differences in routing and more pronounced fractionation during synthesis of collagen (the main organic component of skeletal tissues) compared to bioapatite (Tuross et al., 2008; Kirsanow et al., 2008; Kirsanow and Tuross, 2011). At the same time, in addition to potentially introducing contaminant oxygen, proteinaceous organic matter also introduces nitrogen to the sample, which can cause isobaric interference during the IRMS measurement. This is caused by the mass equivalence of $\mathrm{N}_{2}$ and the sample gas $\mathrm{CO}$, which means that IRMS measurements can be shifted to lower $\delta^{18} \mathrm{O}$ values if the two gases are not sufficiently separated by the GC column of the TC/EA (Farquhar et al., 1997; Fourel et al., 2011; Qi et al., 2011; Hunsinger and Stern, 2012). Both of these aspects are especially relevant for analyses conducted on bioapatite of bone or tooth dentine, as, even when taken from archaeological contexts, these tissues can include a relatively high proportion of organic material (ca. $25 \%$ and $18 \%$ respectively in vivo), compared to the almost exclusively inorganic dental enamel (less than 1\% protein) (Eastoe, 1979; Williams and Elliott, 1989; Walsh et al., 2003; Hillson, 2005), and therefore carry an elevated risk of introducing organic contamination or suffering from issues with isobaric interference from $\mathrm{N}_{2}$.

Additionally, it has been proposed that the presence of organic matter may interfere with routine silver phosphate sample preparation. Organic material could, for instance, prevent complete dissolution of bioapatite, which could introduce fractionation effects and affect $\mathrm{Ag}_{3} \mathrm{PO}_{4}$ yields (O'Neil et al., 1994). If this were the case, it would therefore be vital that sample treatments are designed to ensure complete bioapatite dissolution and to produce silver phosphates that are free from organic contamination. In this study we aim to identify a reliable approach to obtaining faithful $\delta^{18} \mathrm{O}$ values from bioapatite phosphate, particularly from organic rich skeletal materials such as bone, and reassess the need for organic removal pretreatments.

\subsection{Silver phosphate sample preparation methods}

Bioapatite phosphate is commonly isolated as silver phosphate $\left(\mathrm{Ag}_{3} \mathrm{PO}_{4}\right)$ for IRMS analysis, following development of this method by Crowson et al. (1991) based on previous work by Wright and Hoering (1989) and Firsching (1961) to replace older techniques using bismuth phosphate $\left(\mathrm{BiPO}_{4}\right)$. To produce silver phosphate, sample preparation methods broadly follow a two-step approach in which bioapatite samples are dissolved in hydrofluoric acid (HF), which breaks the calcium-phosphate bond and removes calcium by prepipitating $\mathrm{CaF}_{2}$, after which silver phosphate is quantitatively precipitated from the resulting solution.

In most protocols the precipitation of silver phosphate occurs slowly over several hours after addition of ammoniacal silver ammine solution as the solution $\mathrm{pH}$ decreases through outgassing of ammonia (Crowson et al., 1991; Lécuyer et al., 1993). Alternatively, a rapid precipitation can be employed, where the solution pH is buffered 
with $\mathrm{NH}_{4} \mathrm{OH}$ and addition of silver nitrate solution causes instantaneous precipitation of silver phosphate (Dettman et al., 2001). Use of a rapid precipitation protocol significantly reduces sample preparation time and both methods were tested to yield equivalent $\delta^{18} \mathrm{O}$ results using NIST SRM 120c (formerly NBS 120c; Dettman et al., 2001), a phosphorite rock standard from Miocene marine deposits in Florida. However, there has so far been no published comparison of the methods with regards to performance on materials with higher content of organic material.

Independent of precipitation method, sample preparation can include an additional purification step using an anion exchange resin, which is used prior to silver phosphate precipitation (e.g. Crowson et al., 1991; Lécuyer et al., 1993; Lécuyer, 2004; Daux et al., 2008). Resins such as Amberlite or Amberjet resin are used to selectively bind the trivalent phosphate ions, that can be later eluted from the resin, isolating phosphate ions from other compounds in the solution (Crowson et al., 1991; Lécuyer, 2004). While this anion exchange step is theoretically independent of precipitation method, it has so far only been employed in conjunction with slow precipitation protocols. Again, as with the different precipitation methods, while it has been hypothesized by Lécuyer (2004) that the use of resin purification could prevent organic contamination, no detailed investigations of the effects of this step of organic-rich samples has been published so far.

\subsection{Common pretreatment methods for biological samples}

A variety of pretreatment methods are currently in use for treating bone, dentine and tooth enamel samples prior to silver phosphate preparation. While some researchers recommend forgoing the use of pretreatments, they are used by the vast majority of research groups, particularly for substrates where a high organic content is assumed (e.g. bone). Pretreatments are mostly designed to remove organic material, but other aspects such as ensuring complete bioapatite dissolution are also a concern. Among the different organic removal pretreatments, most commonly either hydrogen peroxide $\left(\mathrm{H}_{2} \mathrm{O}_{2}\right)$ or sodium hypochlorite $(\mathrm{NaOCl})$ are used to oxidise organic material. Following initial recommendation by O'Neil et al. (1994), $\mathrm{H}_{2} \mathrm{O}_{2}$ is usually employed as a $30 \%$ solution either at room temperature (e.g. O'Neil et al., 1994; Delgado Huertas et al., 1995; Koch et al., 1997; Britton et al., 2015) or at $80^{\circ} \mathrm{C}$ (Pellegrini et al., 2008; Snoeck and Pellegrini, 2015). Fewer studies employ $\mathrm{H}_{2} \mathrm{O}_{2}$ diluted to $3 \%$ or $5 \%$ strength (Cerling and Harris, 1999; Passey et al., 2005). This pretreatment is recommended for instance in O'Neil et al. (1994). Grimes and Pellegrini (2013) on the other hand have found indications that $\mathrm{H}_{2} \mathrm{O}_{2}$ pretreatment may alter the pristine isotopic composition of bioapatite phosphate, while also not removing all organic material. $\mathrm{NaOCl}$ is also widely used, most often with a concentration between 2\% and 5\% (Quade et al., 1992; Stephan, 2000; Arppe and Karhu, 2006; Tütken et al., 2006; Pucéat et al., 2010). While this bleach pretreatment is recommended by some (e.g. Stephan, 2000; Wiedemann-Bidlack et al., 2008; Shabaga et al., 2018), other researchers have suggested that it may have undesirable side effects on $\delta^{18} \mathrm{O}_{\text {phos }}$ (Grimes and Pellegrini, 2013). Some researchers also emphasize the potential of the organic matrix to hinder the dissolution of bioapatite samples (e.g. O'Neil et al., 1994). Some protocols therefore include the dissolution of samples in nitric acid $\left(\mathrm{HNO}_{3}\right)$ prior to silver phosphate preparation (e.g. Wiedemann-Bidlack et al., 2008). 


\subsection{Establishing pretreatment and preparation method effects}

Previous studies on pretreatment methods to process bone, dentine or enamel samples have used several different approaches to evaluate the effectiveness of the different pretreatment protocols. The different approaches used to assess pretreatment methods may in part be responsible for the widespread disagreement on which pretreatment - if any - should be used for each sample type. In addition, the use of different sample substrates (archaeological and modern) with varying sample characteristics in pretreatment experiments, coupled with modest sample numbers, have led to confusing, and sometimes contradictory, results. For preparation methods, different methods have been shown to be comparable in terms of $\delta^{18} \mathrm{O}$ values they yield for inorganic or low organic samples such as synthetic hydroxyapatites, tooth enamel or the NIST SRM 120c standard (Crowson et al., 1991; Lécuyer et al., 1993; O'Neil et al., 1994; Dettman et al., 2001; but see Mine et al., 2017 for concerns regarding microprecipitations). To date, however, the use of anion exchange resin or differences in precipitation method have not been evaluated in terms of their performance on bone samples specifically.

The efficiency of organic-removal pretreatments is commonly assessed using techniques to determine the purity of silver phosphate and/or the amount of remaining organic material either in pretreated bone or precipitated silver phosphate (e.g. Wiedemann-Bidlack et al., 2008; Grimes and Pellegrini, 2013; Snoeck and Pellegrini, 2015). For example, FTIR or \% $\mathrm{N}$ by EA-IRMS can be used in order to quantify remaining organic content of the pretreated sample substrate or of the final silver phosphate (Grimes and Pellegrini, 2013; Snoeck and Pellegrini, 2015). To evaluate whether silver phosphate has formed in the expected crystal structure, studies also employ a variety of crystal structure analysis methods such as X-Ray Diffraction (XRD) or Scanning Electron Microscopy (SEM) (e.g. Shabaga et al., 2018; Grimes and Pellegrini, 2013; Crowley and Wheatley, 2014). In a number of studies the colour of silver phosphate crystals has also been used to infer organic content (e.g. Stephan, 2000; Crowson et al., 1991; Wiedemann-Bidlack et al., 2008), although this has been deemed by others as an unreliable indicator of silver phosphate purity (e.g. Grimes and Pellegrini, 2013). It should be noted that, while measures of organic content in silver phosphate or pretreated bone give important indications of pretreatment efficiency, they do not inform us as to the isotopic consequences of pretreatment, particularly any undesirable side effects on the inorganic matrix (e.g. Pellegrini and Snoeck, 2016). These pretreatment 'effects' must therefore be discerned via other means.

Most pretreatment studies test the effect of the pretreatment or the equivalency of two preparation methods on an inorganic substance of known isotopic value: the phosphorite rock standard NIST SRM 120c (formerly NBS 120c) is commonly used (e.g. Wiedemann-Bidlack et al., 2008; Shabaga et al., 2018), the assumption being that a pretreatment should not have any effects on the isotopic composition of an inorganic substance.

It should be noted however, that mostly inorganic substances such as NIST SRM 120c or even tooth enamel may not present an ideal proxy for bone bioapatite. Due to its more porous and less crystalline nature, bone bioapatite may be more susceptible to pretreatment side effects, and there is little consensus on how to establish whether isotopic effects caused by pretreatment of bone materials are desirable and caused by organic removal or 
undesirable and caused by isotopic effects on the mineral matrix. Grimes and Pellegrini (2013) approached this issue by comparing $\delta^{18} \mathrm{O}$ values of drinking water reconstructed from bioapatite $\delta^{18} \mathrm{O}$ values of both modern and archaeological animals to precipitation $\delta^{18} \mathrm{O}$ values at the known or presumed animal origin. On this basis they concluded that $\delta^{18} \mathrm{O}$ values of untreated samples (bone, dentine and enamel) was consistent with the range of the 'true values' established in this way. However, this appraoch may not be ideal due to concerns with the accuracy of drinking water conversions in general (e.g. Daux et al., 2008; Pollard, 2011), as well as potential issues with diagenetic change or unknown animal origin when applied to archaeological materials.

\section{Materials and methods}

An overview of the experimental and analytical workflow of this study can be found in Figure 1. In this study, we evaluate the performance of two different silver phosphate preparation methods in preventing the inclusion of organic material in precipitated silver phosphate. We compare a slow precipitation (including anion exchange purification) approach (Preparation A) to a rapid precipitation technique without a purification step (Preparation B). By establishing the baseline performance of the different preparation methods without pretreatment (Pretreatment 4), we then explore the necessity of a pretreatment step. We then assess the performance of the commonly used $\mathrm{H}_{2} \mathrm{O}_{2}$ and $\mathrm{NaOCl}$ pretreatments (Pretreatment 1 and Pretreatment 2) regarding removal of organic material and potential side effects (see above). We additionally investigate the effects of the organic matrix on bioapatite dissolution and test the effects of nitric acid pre-dissolution in this regard (Pretreatment 3). A number of different materials were used in this study to address different aspects of our research questions, including modern and archaeological biogenic materials, and synthesised and standard materials. 


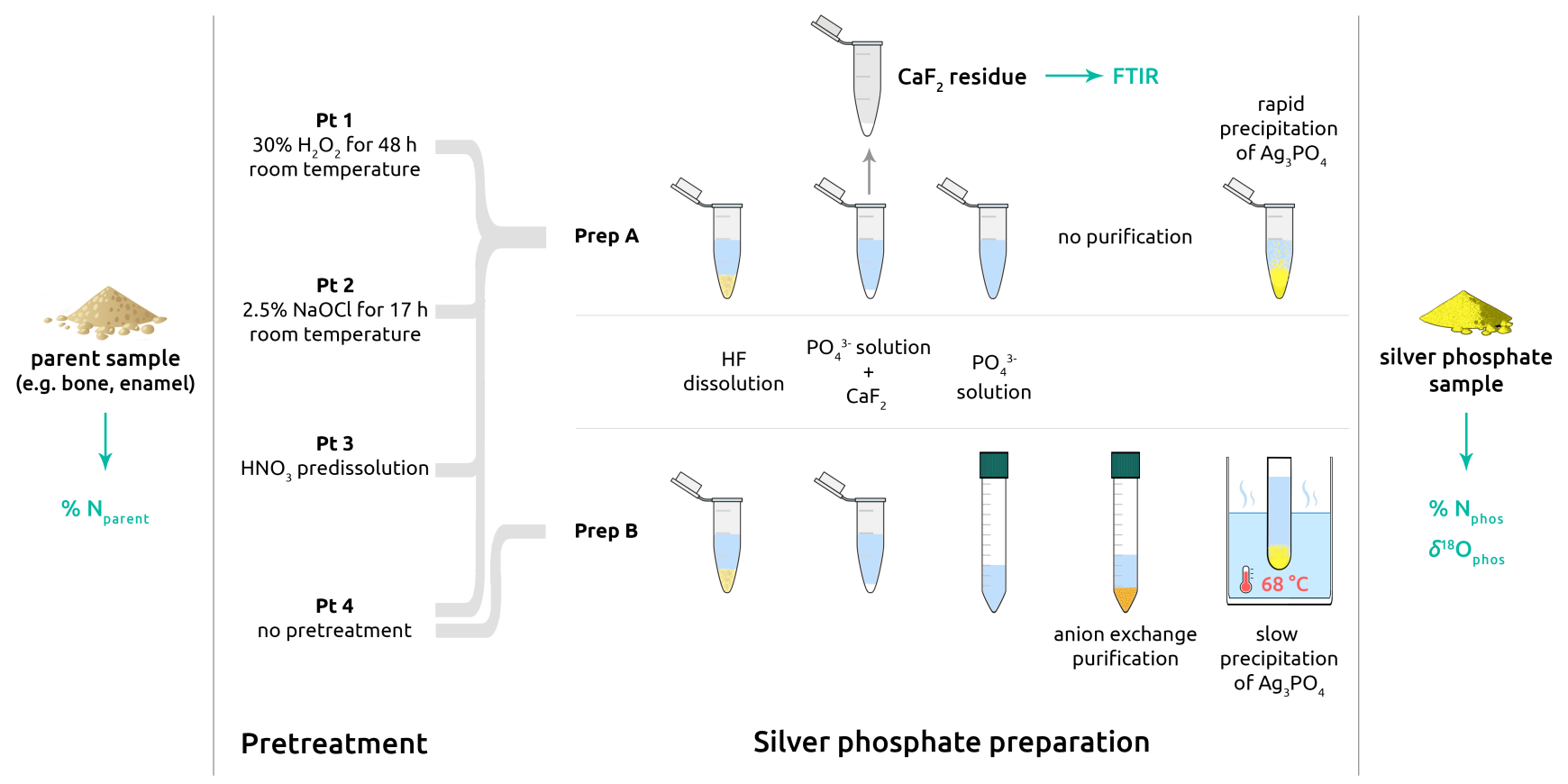

Figure 1: Schematic overview of experimental and analytical workflow of this study including pretreatment techniques, silver phosphate preparation and sample analyses (green).

\subsection{Samples}

A list of all materials used in this study can be found in Table 1. A number of in-house biological samples were used to test the effects of pretreatement and preparation methods: two modern bone samples (WMB14B, BRWB), two modern enamel samples (WMB14E, BRWE) and one modern dentine sample (WMB14D), as well as two archaeological bones (S-EVA-2000, S-EVA-2001). Some of these samples originate from the same individual (WMB14B, WMB14D and WMEB14E from modern bison as well as BRWB and BRWE from a modern domestic cow). Additionally, a number of commercially available standard materials (NIST SRM 120c phosphorite rock, NIST SRM 1400 ashed bone, and NIST SRM 1486 bone meal) and a commercially available hydroxyapatite (HAP - a reagent grade hydroxyapatite, 289396-25G, Sigma Aldrich, Steinheim, Germany) were used. To test pretreatment and preparation methods on samples with more well established true isotopic values and determined collagen content we additionally used three sets of hydroxyapatite/collagen mixtures to approximate synthetic bones with a known inorganic hydroxyapatite component. The first set of synthetic bones (1400.C, 1400.C.5, 1400.C.15 and 1400.C.20) were produced by mechanically mixing NIST SRM 1400 ashed bone with known quantities of collagen $(23 \%, 5 \%$, $10 \%, 15 \%, 20 \%)$. The collagen was extracted prior to this study from a medieval pig bone from Rennes, France, following the protocol outlined in Colleter et al. (2017). The second set of synthetic bones (HAP.C.5, HAP.C.10, HAP.C.15 and HAP.C.20) were produced in the same way using HAP commercial hydroxyapatite as the inorganic fraction mixed with $5 \%, 10 \%, 15 \%$ or $20 \%$ of pig collagen respectively. The third set of synthetic bones consists of a commercially available surgical bone substitute (BOC, Bio-Oss Collagen), which is supplied containing $10 \%$ pig 
Table 1: Overview of samples with information on type, age and approximate collagen content (calculated from $\% \mathrm{~N}_{\text {parent }}$, available in the Supplementary Data S1).

\begin{tabular}{|c|c|c|c|c|}
\hline No & Sample code & Sample material & Age & $\%$ collagen \\
\hline 1 & WMB14B & Bison bone & Modern & 20.3 \\
\hline 2 & WMB14D & Bison dentine & Modern & 15 \\
\hline 3 & WMB14E & Bison enamel & Modern & bdl \\
\hline 4 & BRWB & Cow bone & Modern & 22.5 \\
\hline 5 & BRWE & Cow enamel & Modern & bdl \\
\hline 6 & $\mathrm{BOH}$ & Bio-Oss synthetic hydroxyapatite bone substitute & Modern & 0 \\
\hline 7 & $\mathrm{BOC}$ & Bio-Oss bone subsitute with pig collagen & Modern & 10 \\
\hline 8 & S-EVA-2000 & Mammoth bone & Pleistocene & 15.4 \\
\hline 9 & S-EVA-2001 & Woolly rhinocerus bone & Pleistocene & 11.2 \\
\hline 10 & NIST SRM 120c & Florida Phosphate rock & Modern & 0 \\
\hline 11 & NIST SRM 1400 & Ashed bone & Modern & 0 \\
\hline 12 & NIST SRM 1486 & steamed cow bone meal & Modern & 11.3 \\
\hline 13 & 1400.C & NIST SRM 1400 with $\sim 23 \%$ medieval pig collagen & Modern/Medieval & 23 \\
\hline 14 & 1400.C.5 & NIST SRM 1400 with $\sim 5 \%$ medieval pig collagen & Modern/Medieval & 5 \\
\hline 15 & 1400.C.10 & NIST SRM 1400 with $\sim 10 \%$ medieval pig collagen & Modern/Medieval & 10 \\
\hline 16 & 1400.C.15 & NIST SRM 1400 with $\sim 15 \%$ medieval pig collagen & Modern/Medieval & 15 \\
\hline 17 & 1400.C.20 & NIST SRM 1400 with $\sim 20 \%$ medieval pig collagen & Modern/Medieval & 20 \\
\hline 18 & HAP & Synthetic hydroxyapatite powder & Modern & 0 \\
\hline 19 & HAP.C.5 & HAP with $\sim 5 \%$ medieval pig collagen & Modern/Medieval & 5 \\
\hline 20 & HAP.C.10 & HAP with $\sim 10 \%$ medieval pig collagen & Modern/Medieval & 10 \\
\hline 21 & HAP.C.15 & HAP with $\sim 15 \%$ medieval pig collagen & Modern/Medieval & 15 \\
\hline 22 & HAP.C. 20 & HAP with $\sim 20 \%$ medieval pig collagen & Modern/Medieval & 20 \\
\hline
\end{tabular}

collagen of unspecified origin as well as the synthetic hydroxyapatite (BOH, Bio-Oss) that is used as the inorganic component of this product. Both products were obtained from Geistlich Pharma (Wolhusen, Switzerland). These mixtures were used to obtain a sample substrate with a chemical composition similar to bone, but with a known true isotopic value of the mineral fraction. In this way we attempt to approximate how the presence of organic material might influence measured oxygen isotope ratios and how different treatments might affect a bone sample while at the same time being able to monitor any isotopic effects on the mineral fraction. However, we acknowledge that due to the absence of a true chemical bond between the mineral and the organic fraction in these substrates, they are not true analogues of biological bone samples.

\subsection{Pretreatments}

In this study we evaluate the effects of the two most commonly used organic removal pretreatment methods: hydrogen peroxide $\left(\mathrm{H}_{2} \mathrm{O}_{2}\right.$, Pretreatment 1) and sodium hypochlorite (NaOCl, Pretreatment 2). Additionally, the effects of nitric acid pre-dissolution on bioapatite dissolution efficiency (Pretreatment 3) were tested. These pretreatments are compared against the baseline performance of different silver phosphate preparations (see section 2.3 without pretreatment (Pretreatment 4). All pretreatment tests of pretreatments 1 to 3 were conducted with an initial pretreatment of the materials followed by silver phosphate preparation using rapid precipitation without anion exchange purification (Preparation A) as described in section 2.3.1. All methods are denoted as their respective combinations of pretreatment and preparation method, e.g. hydrogen peroxide pretreatment with rapid precipitation 
would be Pt1-PrepA. Due to initial positive evaluation of Preparation B baseline performance in producing organic free silver phosphates, further tests in combination with organic removal pretreatments were not conducted, as a comprehensive test of all possible combinations of pretreatments and preparation methods is beyond the scope of this study.

\subsubsection{Hydrogen peroxide pretreatment (Pretreatment 1)}

Hydrogen peroxide pretreatment followed a modified version of the protocol initially proposed by O'Neil et al. (1994), a detailed description of which can be found in Britton et al. (2015). To approximately $15 \mathrm{mg}$ of each sample an individually adjusted amount of $30 \% \mathrm{H}_{2} \mathrm{O}_{2}(40 \mu \mathrm{L} / \mathrm{mg}$ sample) was added and samples agitated at room temperature for 48 hours. After this time the $\mathrm{H}_{2} \mathrm{O}_{2}$ solution was removed and each sample rinsed 4 times with $1 \mathrm{~mL}$ MilliQ ultrapure water and then dried over night at $50{ }^{\circ} \mathrm{C}$.

\subsubsection{Sodium hypochlorite pretreatment (Pretreatment 2)}

Sodium hypochlorite pretreatment was modified after Wiedemann-Bidlack et al. (2008) and Stephan (2000). To approximately $15 \mathrm{mg}$ of each sample $1.5 \mathrm{~mL}$ of $2.5 \% \mathrm{NaOCl}$ were added and samples left to react on an agitator for $17 \mathrm{hrs}$. The $\mathrm{NaOCl}$ solution was then removed and the samples rinsed four times with $1 \mathrm{~mL}$ MilliQ ultrapure water and then dried over night at $50{ }^{\circ} \mathrm{C}$.

\subsubsection{Nitric acid pre-dissolution (Pretreatment 3)}

For a subset of bone and inorganic materials, a $\mathrm{HNO}_{3}$ pre-dissolution protocol was tested to evaluate whether incomplete dissolution of bioapatite in bone samples presents an issue. The protocol was adapted from O'Neil et al. (1994). $5 \mathrm{mg}$ of each sample were dissolved in $0.4 \mathrm{~mL}$ of $2 \mathrm{M} \mathrm{HNO}_{3}$ and left over night. Sample solutions were then neutralized to $\mathrm{pH} 7$ using approximately $0.45 \mathrm{~mL}$ of $2 \mathrm{M} \mathrm{KOH}$. The resulting neutral solution was used to proceed with silver phosphate preparation as usual. This pretreatment was primarily used to study the necessity of a pre-dissolution step, and silver phosphates generated from this pretreatment were not analysed for their oxygen isotope composition after evaluation of initial results.

\subsection{Silver phosphate preparation methods}

To assess pretreatment necessity we first establish baseline performance of different silver phosphate preparation methods (Figure 1). We compare two commonly employed methods: a rapid precipitation method without purification step following Dettman et al. (2001) and modified by Tütken et al. (2006) (referred to as Preparation A here) and a slow precipitation method with an anion exchange purification step following a modified version of a protocol outlined in Lécuyer et al. (1993) and Lécuyer et al. (2007) (Preparation B). 


\subsubsection{Rapid precipitation without purification (Preparation A)}

Rapid precipitation procedures were conducted at the Max-Planck-Institute for Evolutionary Anthropology (MPI EVA) following the protocol as described in Britton et al. (2015), based on the method developed by Dettman et al. (2001) and modified by Tütken et al. (2006), with some alteration to accommodate the experimental set up of the study. Approximately $10 \mathrm{mg}$ of each sample were agitated in $0.8 \mathrm{~mL} 2 \mathrm{M}$ HF for $24 \mathrm{hrs}$. The supernatant solution was removed from resulting calcium fluoride $\left(\mathrm{CaF}_{2}\right)$ residue and the $\mathrm{CaF}_{2}$ residue then washed with $0.1 \mathrm{~mL}$ Milli-Q ultrapure water and the wash added to the rest of the phosphate solution. $\mathrm{CaF}_{2}$ residues are usually discarded in this protocol, but were kept in this study to determine if bioapatites had completely dissolved (see Figure 1 and section 2.5). For safety reasons, $0.2 \mathrm{~mL}$ of $2 \mathrm{M}$ potassium hydroxide $(\mathrm{KOH})$ were added to $\mathrm{CaF}_{2}$ residues to neutralise any remaining solution. The solution was then removed from the $\mathrm{CaF}_{2}$ residue and the residue rinsed to neutrality using three Milli-Q water rinses. To precipitate $\mathrm{Ag}_{3} \mathrm{PO}_{4}$ phosphate solutions were first neutralized to the colour change point of Bromthymol Blue using individually adjusted amounts of $25 \%$ ammonia solution $\left(\mathrm{NH}_{4} \mathrm{OH}\right)$ coming up to ca. $0.17 \mathrm{~mL}$. Silver phosphate was then rapidly precipitated by adding $0.8 \mathrm{~mL} 2 \mathrm{M}$ silver nitrate $\left(\mathrm{AgNO}_{3}\right)$ solution, the supernatant solution discarded and the precipitate then rinsed four times with MilliQ ultrapure water to remove any remnants of silver nitrate. Both $\mathrm{Ag}_{3} \mathrm{PO}_{4}$ and $\mathrm{CaF}_{2}$ samples were then dried over night at $50^{\circ} \mathrm{C}$.

\subsubsection{Anion exchange purification with slow precipitation (Preparation B)}

Slow precipitation preparations with anion exchange purification were conducted at the Vreije Universiteit Brussel (VUB) following a protocol modified after Lécuyer et al. (1993). Approximately $10 \mathrm{mg}$ of each sample were digested in $0.67 \mathrm{~mL}$ of $2 \mathrm{M} \mathrm{HF}$ for $24 \mathrm{hrs}$. The supernatant solution containing the phosphate moiety was removed from $\mathrm{CaF}_{2}$ residue into a $10 \mathrm{~mL}$ plastic test tube and the $\mathrm{CaF}_{2}$ residue was then rinsed with $0.67 \mathrm{~mL}$ Milli-Q ultrapure water three times. The MilliQ ultrapure water from each rinse was added to the $10 \mathrm{~mL}$ test tube. Individually adjusted amounts of $2 \mathrm{M} \mathrm{KOH}$ (usually between 360 and $375 \mu \mathrm{L}$ ) were added to bring the solution to $6<\mathrm{pH}<8.0 .83 \mathrm{~mL}$ of cleaned Amberlite anion exchange resin (Amberlite IRN78 hydroxide form, Sigma Aldrich, Steinheim, Germany) was agitated in the sample solution for $24 \mathrm{hrs}$. After this time, the supernatant solution discarded, and the loaded resin retained. The resin was then rinsed to neutrality using three rinses of $1.3 \mathrm{~mL}$ of Milli-Q ultrapure water. To release the resin bound phosphate, $9.17 \mathrm{~mL}$ of $0.5 \mathrm{M} \mathrm{NH}_{4} \mathrm{NO}_{3}$ were then added to achieve a basic pH between 7.5 and 8.5 and the samples agitated for $4 \mathrm{hrs}$. The supernatant solution containing the purified phosphate was then removed to glass test tubes. The resin was then rinsed twice with $1.25 \mathrm{~mL}$ MilliQ ultrapure water. Concentrated $\mathrm{NH}_{4} \mathrm{OH}(170 \mu \mathrm{L})$ was then added to each sample to adjust the $\mathrm{pH}$ and prevent the immediate precipitation of silver phosphate. $5 \mathrm{~mL}$ of $0.2 \mathrm{M}$ ammoniacal AgNO3 were added to the adjusted solutions and all tubes were placed in a heated water bath at $68{ }^{\circ} \mathrm{C}$ over night, allowing silver phosphate crystals to form. After completion of this reaction, the solution was removed from each test tube and the crystals rinsed two times with Milli-Q ultrapure water. The crystals were then dried at $50{ }^{\circ} \mathrm{C}$ for $12 \mathrm{hrs}$. 


\subsection{Stable isotope analyses}

All silver phosphate precipitates except samples pre-dissolved in nitric acid (Pretreatment 3) were measured for their oxygen isotope composition. Oxygen isotope measurements of silver phosphate samples were conducted using a High Temperature Elemental Analyser (TC/EA) coupled to a Delta V Advantage isotope ratio mass spectrometer via a Conflo IV interface (Thermo Fisher Scientific, Bremen, Germany) at the Max-Planck-Institute for Evolutionary Anthropology. Approximately $0.5 \mathrm{mg}$ of silver phosphate samples were weighed into silver capsules and introduced into the TC/EA using a Costech Zero Blank Autosampler (Costech Inernational, Cernusco sul Naviglio, Italy). The reactor tube was maintained at $1450{ }^{\circ} \mathrm{C}$. Gas peak separation was achieved using an Agilent Technologies $0.6 \mathrm{~m}$ x 1.4" x 4 mm stainless steel GC column with 80/100 mesh $5 \AA$ molecular sieve packing (IVA Analysentechnik, Meerbusch, Germany) maintained at $80{ }^{\circ} \mathrm{C}$ with a column carrier gas flow of $100 \mathrm{~mL} / \mathrm{min}$. Samples were usually measured in triplicate except in cases where additional measurements were conducted to improve the measurement precision or if individuals measurements failed to conform to quality control criteria such as an acceptable sample amount to peak area relationship. Information on the number of replicates measured for each sample can be found in the stable isotope supplementary data set (Supplementary Data S1, S1_d18O.csv). Reproducibility of repeat measurements was $0.2 \%$ on average, however it should be noted that several treatment comparisons in this study rely on computed difference between two measurements, which will be associated with a propagated error of the sum of the individual measurement uncertainties. The standard deviation of all replicates is given for each sample in Table 3. All sample $\delta^{18} \mathrm{O}$ values were scale normalized and calibrated to the international VSMOW scale using the $\mathrm{B} 2207$ silver phosphate standard $\left(\delta^{18} \mathrm{O}=21.7 \pm 0.3 \%\right.$, 1 s.d.; Elemental Microanalysis, Okehampton, UK) and an in-house silver phosphate standard $\left(\delta^{18} \mathrm{O}=4.2 \pm 0.3 \%\right.$, 1 s.d. $)$. This in-house standard was obtained by equilibrating a $\mathrm{KH}_{2} \mathrm{PO}_{4}$ solution with Leipzig winter precipitation at ca. $140{ }^{\circ} \mathrm{C}$ for several days, after which the solution was neutralized using a small amount of $\mathrm{NH}_{4} \mathrm{OH}$ and the phosphate precipitated as silver phosphate by adding $\mathrm{AgNO}_{3}$. The accepted value of this in-house standard was determined by two-point calibration using B2207 and IAEA-SO-6 (barium sulfate, $\delta^{18} \mathrm{O}=-11.35 \pm 0.3 \%$ o, 1 s.d., as given in Brand et al. (2009)). Aliquots of an in-house modern cow bone standard (BRWB) were precipitated and measured alongside each batch of samples to ensure equal treatment. Measurements of this standard gave a mean $\delta^{18} \mathrm{O}$ value of $15.0 \%$ with an average within-run standard deviation of $0.2 \%$ (1 s.d.) and an across run standard deviation of $0.4 \%$ (1 s.d.). Consecutive analysis of sets of standards with widely spaced isotopic value showed no detectable memory effect and consequently no memory effect correction was used. No effect of the blank or of the sample amount or peak height on the results was observed and consequently no blank correction or linearity correction was used. To correct for slight drift observed in standards measured over the course of a run a linear drift correction based on the drift of both normalization standards was used, and checked with the quality control standard. 


\subsection{ATR-FTIR analyses of $\mathrm{CaF}_{2}$ residues}

To determine if dissolution of bioapatite was completed during HF digestion, even in the presence of high amounts of organic matter, we tested $\mathrm{CaF}_{2}$ residues for any traces of undissolved bioapatite using ATR-FTIR. Spectra were recorded at $4 \mathrm{~cm}^{-1}$ resolution using an Agilent 660 FTIR Spectrometer (Agilent Technologies, Waldbronn, Germany) with a DTGS detector fitted with an accessory GladiATR ${ }^{\mathrm{TM}}$ (Pike Technologies, Madison, Wisconsin, USA) with a diamond crystal. Each spectrum was generated by averaging 32 scans between 4000 and $400 \mathrm{~cm}^{-1}$.

The detection limit of bioapatite residues in $\mathrm{CaF}_{2}$ was determined by analysing a series of mixtures of Sigma Aldrich synthetic hydroxyapatite (HAP) with a Sigma Aldrich commercial calcium fluoride. The most persistent bioapatite phosphate peak was detected at $1023 \mathrm{~cm}^{-1}$, and could not be detected in samples below $3 \% \mathrm{HAP}$ in $\mathrm{CaF}_{2}$. This detection limit corresponds to an approximate sample loss of $1 \%$ in a $10 \mathrm{mg}$ bioapatite sample.

\section{6. $\% N$ analyses of silver phosphates}

To evaluate the inclusion of contaminant nitrogenous organic compounds in silver phosphate prepared using the different protocols outlined above we assessed the amount of organic matter included in silver phosphate samples using $\% \mathrm{~N}$ measurements made by EA-IRMS. \% $\mathrm{N}$ was chosen as a proxy for organic content over FTIR following recommendations by Snoeck and Pellegrini (2015). An Elemental Analyser set up similar to that used by Grimes and Pellegrini (2013) was used to ensure that results are readily comparable to previous work. Analyses were carried out using a Flash EA 1112 Elemental Analyzer (Thermo Fisher Scientific, Bremen, Germany) coupled to a Delta XP ratio mass spectrometer (Thermo Fisher Scientific, Bremen, Germany) via a Conflo III interface (Thermo Fisher Scientific, Bremen, Germany) at the MPI-EVA. Approximately $3 \mathrm{mg}$ of each silver phosphate sample was weighed into tin capsules and introduced to the Elemental Analyzer using an AS 200S autosampler. The oxidation reactor was held at $1020{ }^{\circ} \mathrm{C}$ and the reduction reactor at $650{ }^{\circ} \mathrm{C}$. Due to the use of tin capsules in this method, samples flash combust at approximately $1800{ }^{\circ} \mathrm{C}$ (Fry et al., 1992). The GC column was held at $65{ }^{\circ} \mathrm{C}$ with a carrier gas flow of $115 \mathrm{~mL} / \mathrm{min}$. Different amounts ranging from 0.15 to $0.7 \mathrm{mg}$ of a methionine in-house standard were analysed together with each run of samples to calibrate peak area measurements to \% values. The detection limit of this method is $0.02 \%$, based on peak detection of minimum peak height of $50 \mathrm{mV}$. The precision of $\% \mathrm{~N}$ measurements based on repeat determinations of the methionine standard was on average $0.06 \%$. We estimate that a threshold of $0.2 \% \mathrm{~N}_{\text {phos }}$ is indicative of a sample containing enough collagen to change its isotopic value by more than $0.3 \%$ (see Supplementary Data S2 for details). Above this threshold an isotopic shift larger than this common measurement uncertainty of $0.3 \%$ is possible. This threshold was calculated by estimating the oxygen contribution from collagen using the stoichiometry of the four most abundant amino acids of collagen (glycine, proline, alanine and hydroxyproline). An approximate shift was estimated using this oxygen contribution and published data on the isotopic offset between collagen and bioapatite in bone (data from Warinner and Tuross, 2010; Kirsanow and Tuross, 2011; Crowley and Wheatley, 2014). This isotopic offset varies widely, and seemingly in a species-specific way, based 
on the limited data available. For the purpose of this study we chose an intermediate estimate (i.e. the median of reported offset values) of $8.8 \%$. Our $0.2 \% \mathrm{~N}_{\text {phos }}$ threshold aims to represent a realistic estimate for a potentially isotopically 'problematic' level of collagen in silver phosphate. It should be noted, however, that in many samples, a higher amount of nitrogen may be acceptable. For instance, when using the least conservative estimate (i.e. the smallest phosphate/collagen spacing published) a threshold of $0.6 \% \mathrm{~N}$ as the highest acceptable value is generated. Approximate collagen content of bone and dentine samples was calculated using $\% \mathrm{~N}$ measurements of untreated bone/dentine powder and collagen stoichiometry analogous to the procedure outlined above.

\subsection{Data analysis and manuscript generation}

This article, including code for all data analyses, was written in R (R Core Team, 2017) and generated using RMarkdown (Allaire et al., 2018). All raw data as well as the RMarkdown script to reproduce the article texts and its analyses are included in the Supplementary Data S1 (main manuscript) and Supplementary Data S2 (Suppplementary Information). All data and code are also free to access at the corresponding Open Science Framework project at https://osf.io/ug5k4/. The code for data analysis and manuscript rendering makes use of the forcats (Hadley Wickham, 2018), stringr (H Wickham, 2018a), dplyr (Wickham et al., 2018), purrr (Henry and Wickham, 2018), readr (Wickham et al., 2017), tidyr (Wickham and Henry, 2018), tibble (Müller and Wickham, 2018), tidyverse (H Wickham, 2018b), ggplot2 (Wickham, 2016), bookdown (Xie, 2016), kableExtra (Zhu, 2018), knitr (Xie, 2014), and ggrepel (Slowikowski, 2018) packages.

\section{Results}

\subsection{Effects of $\mathrm{HNO}_{3}$ pretreatment on bioapatite dissolution}

FTIR-ATR spectra of $\mathrm{CaF}_{2}$ residues of untreated modern bone (WMB14B), untreated hydroxyapatite (HAP), $\mathrm{HNO}_{3}$ pre-dissolved (Pt3) WMB14B bone as well as reference spectra for a commercial $\mathrm{CaF}_{2}$ and enamel powder (WMB14E) are shown in Figure 2. When compared to the spectrum of enamel powder, as an indication of where peaks would be expected in the presence of undissolved bioapatite, none of the $\mathrm{CaF}_{2}$ spectra show any peaks matching this reference. In fact, no single $\mathrm{CaF}_{2}$ spectrum shows detectable peaks at all, as would be expected for a pure $\mathrm{CaF}_{2}$ spectrum (see Figure 2, top), due to its transparency to infrared radiation (Malitson, 1963). There additionally is no visible difference between $\mathrm{CaF}_{2}$ spectra from bone samples compared to $\mathrm{CaF}_{2}$ from pure hydroxyapatite. $\mathrm{CaF}_{2}$ yields for bone samples (calculated using approximate sample calcium content and $\mathrm{CaF}_{2}$ stoichiometry) are comparable to other types of samples for unpretreated materials, and usually lie between 80 and $100 \%$. None of the bone samples show higher than expected mass (> $100 \%$ recovery) for $\mathrm{CaF}_{2}$ residues. Silver phosphate yields are on average higher for unpretreated samples of WMB14B bone (mean $=67 \pm 2 \% ; \mathrm{n}=4)$ than for $\mathrm{HNO}_{3}$ pre-dissolved WMB14B samples $($ mean $=62 \pm 3 \% ; \mathrm{n}=4)$. 


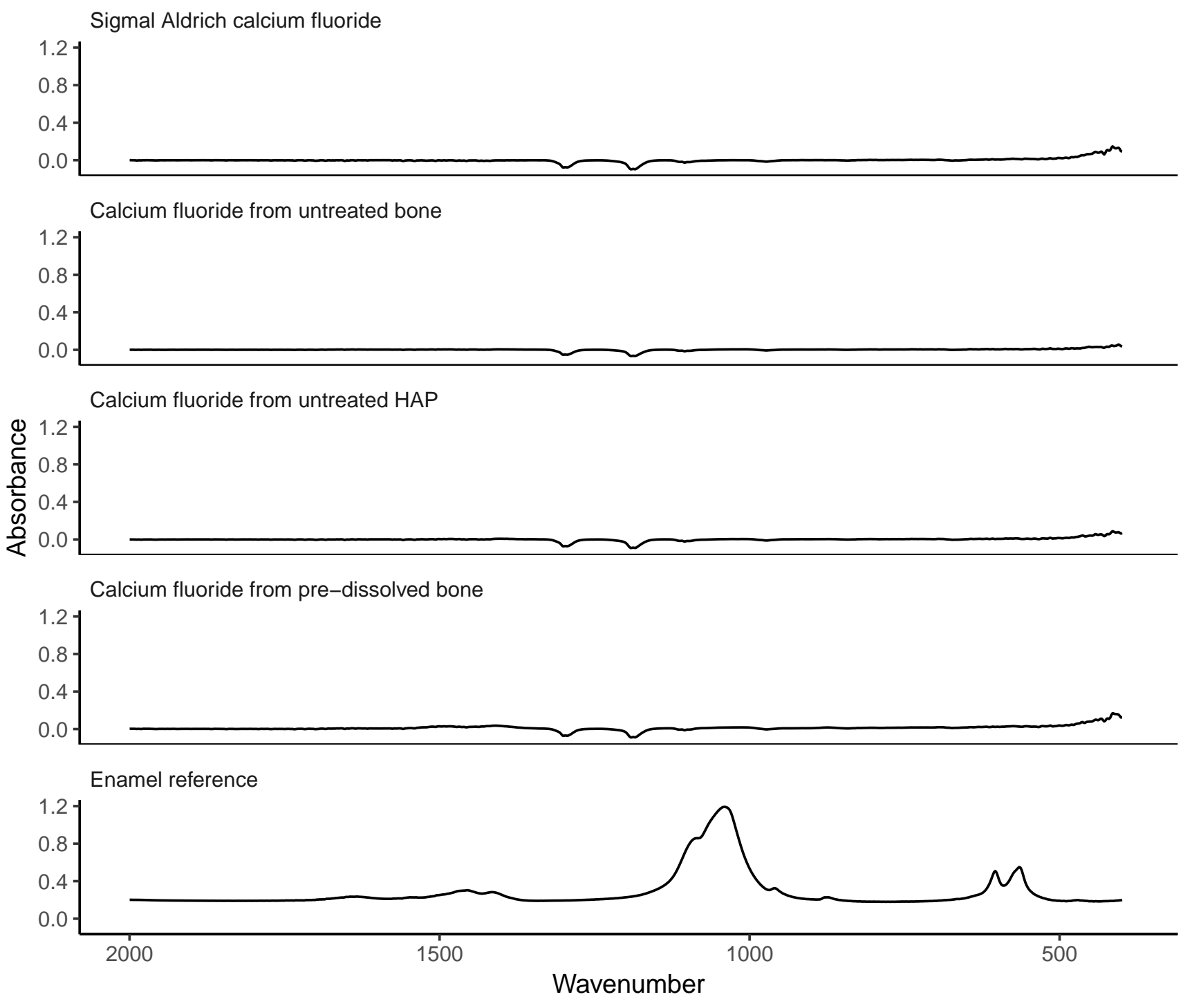

Figure 2: Absence of bioaptite related peaks in FTIR-ATR spectra of calcium fluoride residues from untreated bone, untreated HAP and nitric acid pre-dissolved bone indicate that no bioapatite residues from undissolved sample remain in calcium fluoride powder. All spectra of calcium fluoride residues instead resemble the spectrum for a commercial, pure calcium fluoride (top). An enamel powder reference (bottom) indicates where peaks would be expected in the presence of bioapatite.

\subsection{Effects of preparation methods and pretreatments on $\% N$ in silver phosphate}

Results of $\% \mathrm{~N}$ measurements of silver phosphate samples ( $\left.\% \mathrm{~N}_{\mathrm{phos}}\right)$ prepared using 4 different protocols Pt4-PrepA (Preparation A without pretreatment), Pt4-PrepB (Preparation B without pretreatment), Pt1-PrepA (Preparation A with $\mathrm{H}_{2} \mathrm{O}_{2}$ pretreatment) and Pt2-PrepA (Preparation A with $\mathrm{NaOCl}$ pretreatment) can be found in Table 2.

$\% \mathrm{~N}_{\text {phos }}$ measurements for Pt4-PrepA (rapid precipitation without anion exchange purification and no prior pretreatment) yield markedly higher values than any other preparation method (Figure 3$)($ mean $=0.46$; comparison between methods was conducted using a pairwise Wilcox rank sum test with Bonferoni correction; p(Pt4-PrepA vs Pt4-PrepB $)=10^{-4} ; \mathrm{p}($ Pt4-PrepA vs Pt1-PrepA $)=0.0013 ; \mathrm{p}($ Pt4-PrepA vs Pt2-PrepA $\left.)=6.2 \times 10^{-6}\right)$, indicating that a substantially higher amount of organic matter is included in these silver phosphate samples compared to 
Table 2: $\% \mathrm{~N}$ in silver phosphate samples for each preparation method without preptreatment (Pt4-PrepA and Pt4-PrepB) as well as hydrogen peroxide (Pt1-PrepA) and sodium hypochlorite (Pt2-PrepA) pretreatments. Only samples with proteinaceous components in the parent material are included.

\begin{tabular}{|c|c|c|c|c|c|c|}
\hline No & Sample code & $\%$ collagen original & $\% \mathrm{~N}$ Pt4-PrepA & $\%$ N Pt4-PrepB & $\% \mathrm{~N}$ Pt1-PrepA & $\% \mathrm{~N}$ Pt2-PrepA \\
\hline \multicolumn{7}{|c|}{ Natural Materials } \\
\hline 1 & WMB14B & 20.25 & 0.50 & 0.06 & 0.33 & 0.03 \\
\hline 2 & WMB14D & 14.99 & 0.28 & 0.04 & 0.22 & 0.04 \\
\hline 3 & WMB14E & 1.00 & 0.10 & - & - & - \\
\hline 4 & BRWB & 22.45 & 0.20 & 0.10 & 0.30 & 0.04 \\
\hline 5 & BRWE & 1.00 & 0.10 & - & - & - \\
\hline 8 & S-EVA-2000 & 15.39 & 0.81 & 0.11 & 0.13 & 0.06 \\
\hline 9 & S-EVA-2001 & 11.22 & 0.50 & 0.13 & 0.35 & 0.04 \\
\hline 12 & NIST SRM 1486 & 11.27 & 0.54 & 0.08 & 0.31 & 0.04 \\
\hline \multicolumn{7}{|c|}{ Synthetic Bones } \\
\hline 7 & $\mathrm{BOC}$ & 10.00 & 0.30 & 0.06 & 0.04 & 0.02 \\
\hline 13 & 1400.C & 23.00 & 0.70 & 0.01 & - & - \\
\hline 14 & 1400.C.5 & 5.00 & 0.25 & 0.01 & 0.03 & 0.02 \\
\hline 15 & 1400.C.10 & 10.00 & 0.46 & 0.01 & 0.04 & 0.03 \\
\hline 16 & 1400.C.15 & 15.00 & 0.72 & 0.01 & 0.05 & 0.00 \\
\hline 17 & 1400.C.20 & 20.00 & 0.73 & 0.11 & 0.03 & 0.00 \\
\hline 19 & HAP.C.5 & 5.00 & 0.25 & - & 0.03 & 0.00 \\
\hline 20 & HAP.C.10 & 10.00 & 0.41 & 0.02 & 0.04 & 0.00 \\
\hline 21 & HAP.C. 15 & 15.00 & 0.64 & 0.28 & 0.04 & 0.00 \\
\hline 22 & HAP.C.20 & 20.00 & 0.70 & - & 0.05 & 0.00 \\
\hline- & Mean & - & 0.46 & 0.07 & 0.13 & 0.02 \\
\hline
\end{tabular}

samples from the other preparation methods. The amount of nitrogen in these samples routinely exceeds $0.2 \%$, an intermediate estimate of $\% \mathrm{~N}$ levels indicative of collagen amounts that are likely to lead to $\delta^{18} \mathrm{O}$ changes larger than $0.3 \%$ (see section 2.6 for threshold estimate).

In contrast, Pt4-PrepB (slow precipitation with anion exchange purification) results in consistently low $\% \mathrm{~N}_{\text {phos }}$, even without pretreatment, excepting one slightly higher outlier value for HAP.C.15 (HAP based synthetic bone with $15 \%$ pig collagen). In natural biological materials Pt1-PrepA $\left(\mathrm{H}_{2} \mathrm{O}_{2}\right.$ pretreatment $)$ only results in a modest reduction of $\% \mathrm{~N}_{\text {phos }} \% \mathrm{~N}_{\text {phos }}$ is more strongly reduced in synthetic bones with this pretreatment. This is most likely caused by the higher solubility and vulnerability of artificially added collagen to oxidation treatments compared to collagen that is properly bound to the mineral matrix of a biologically true bone. $\% \mathrm{~N}_{\text {phos }}$ measurements of synthetic bones can therefore not be used to evaluate pretreatment efficiency. Pt2-PrepA ( $\mathrm{NaOCl}$ pretreatment) on the other hand reduces $\% \mathrm{~N}_{\text {phos }}$ in all samples to fall close to the detection limit. In natural materials, the performance of Pt4-PrepB in reducing the inclusion of organic matter cannot be statistically distinguished from that of the NaOCl pretreatment (Pt2-PrepA) as determined by a Wilcox signed rank test $(\mathrm{p}=0.059$; a non-parametric test was chosen due to non-normality of $\% \mathrm{~N}_{\text {phos }}$ measurements for Pt2-PrepA, determined by a Shapiro test; $\mathrm{p}=0.031$ ). 


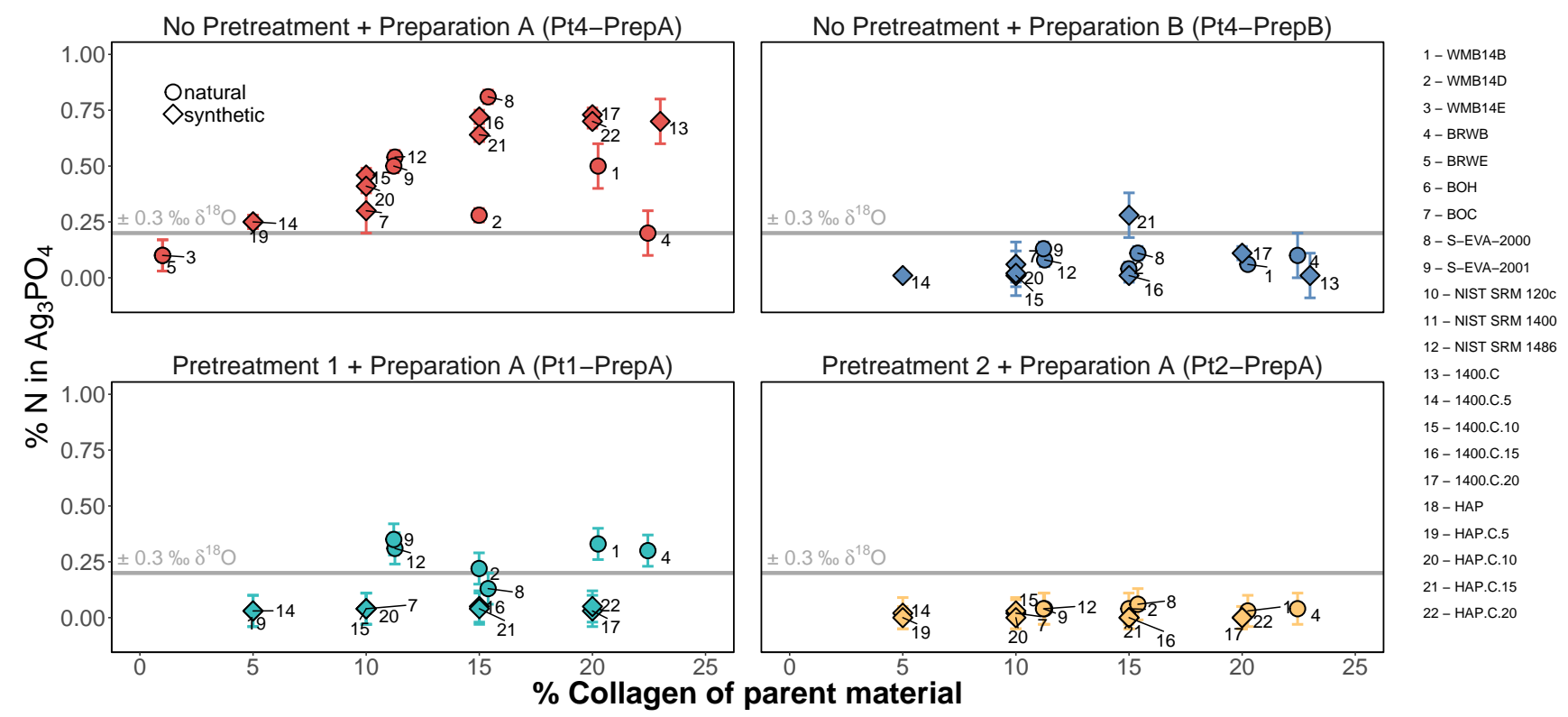

Figure 3: \% $\mathrm{N}$ measurements of silver phosphate sample indicate the amount of contamination with organic matter dependent on the amount of collagen in the parent material for each treatment method. Circles indicate natural biological materials, while diamonds represent synthetic bones. Error bars represent the $\% \mathrm{~N}$ measurement uncertainty (often smaller than point symbols). Grey horizontal lines indicate an estimated threshold of $\% \mathrm{~N}$ above which isotopic shifts larger than $0.3 \%$ omay occurr.

$\% \mathrm{~N}_{\text {phos }}$ values for Pt4-PrepA samples increases in correlation with the collagen content of the original parent material (\% collagen parent ) (Fig.3, top left). This pattern can be observed in natural biological materials containing collagen and synthetic bones with added collagen. $\% \mathrm{~N}_{\text {phos }}$ measurements for enamel however are minimal. In contrast, silver phosphates from Pt4-PrepB show consistently low $\% \mathrm{~N}_{\text {phos }}$ values across the range of $\%$ collagen parent (Fig.3, top right), with the exception of one synthetic bone outlier. For these samples, no correlation with the $\%$ collagen $_{\text {parent }}$ is visible. Neither of the pretreatments show a clear relationship between $\% \mathrm{~N}_{\text {phos }}$ and $\%$ collagen $_{\text {parent }}$ (Fig.3, bottom left and bottom right). However, it can be seen again, that while Pt1-PrepA $\left(\mathrm{H}_{2} \mathrm{O}_{2}\right.$ pretreatment) does reduce $\% \mathrm{~N}_{\text {phos }}$ it does not reduce it to thresholds comparable to Pt4-PrepB or Pt1-PrepA (NaOCl pretreatment) values.

\subsection{Effects of preparation methods and pretreatments on $\delta^{18} \mathrm{O}$}

An overview of the $\delta^{18} \mathrm{O}$ results can be seen in Table 3 . 
Table 3: Overview of $\delta^{18} \mathrm{O}_{\text {phos }}$ values and standard deviations of replication measurements for each sample according to preparation method and organic removal pretreatment employed.

\begin{tabular}{|c|c|c|c|c|c|c|c|c|c|}
\hline No & Sample code & $\begin{array}{r}\text { Pt4-PrepA } \\
\delta^{18} \mathrm{O}_{\text {phos }}\end{array}$ & $\mathrm{SD}$ & $\begin{array}{r}\text { Pt4-PrepB } \\
\delta^{18} \mathrm{O}_{\text {phos }}\end{array}$ & $\mathrm{SD}$ & $\begin{array}{l}\text { Pt1-PrepA } \\
\delta^{18} \mathrm{O}_{\text {phos }}\end{array}$ & $\mathrm{SD}$ & $\begin{array}{r}\text { Pt2-PrepA } \\
\delta^{18} \mathrm{O}_{\mathrm{phos}}\end{array}$ & $\mathrm{SD}$ \\
\hline 1 & WMB14B & 21.1 & 0.4 & 21.2 & 0.2 & 19.8 & 0.2 & 20.9 & 0.0 \\
\hline 2 & WMB14D & 20.4 & 0.2 & 20.7 & 0.2 & 20.0 & 0.3 & 21.1 & 0.1 \\
\hline 3 & WMB14E & 20.6 & 0.4 & 20.9 & 0.3 & 21.2 & 0.2 & 21.4 & 0.2 \\
\hline 4 & BRWB & 15.2 & 0.1 & 14.9 & 0.2 & 14.9 & 0.0 & 15.1 & 0.1 \\
\hline 5 & BRWE & 14.9 & 0.3 & 14.7 & 0.2 & 14.8 & 0.1 & 15.1 & 0.3 \\
\hline 6 & $\mathrm{BOH}$ & 18.7 & 0.1 & 19.2 & 0.2 & 18.9 & 0.3 & 18.8 & 0.3 \\
\hline 7 & $\mathrm{BOC}$ & 18.4 & 0.4 & 19.0 & 0.1 & 18.6 & 0.2 & 18.6 & 0.5 \\
\hline 8 & S-EVA-2000 & 16.5 & 0.3 & 17.0 & 0.2 & 17.9 & 0.1 & 17.8 & 0.3 \\
\hline 9 & S-EVA-2001 & 16.6 & 0.2 & 17.2 & 0.7 & 16.8 & 0.2 & 17.5 & 0.1 \\
\hline 10 & NIST SRM 120c & 21.8 & 0.5 & 22.2 & 0.1 & 22.1 & 0.2 & 21.8 & 0.1 \\
\hline 11 & NIST SRM 1400 & 16.7 & 0.2 & 16.1 & 0.2 & 16.7 & 0.1 & 17.0 & 0.3 \\
\hline 12 & NIST SRM 1486 & 12.4 & 0.3 & 11.9 & 0.4 & 12.2 & 0.2 & 12.6 & 0.3 \\
\hline 13 & 1400.C & - & - & 16.3 & 0.2 & - & - & - & - \\
\hline 14 & 1400.C.5 & 16.0 & 0.2 & 16.0 & 0.3 & 16.5 & 0.1 & 16.6 & 0.2 \\
\hline 15 & 1400.C.10 & 16.0 & 0.1 & 16.2 & 0.3 & 16.4 & 0.0 & 16.7 & 0.1 \\
\hline 16 & 1400.C.15 & 15.9 & 0.0 & 16.3 & 0.5 & 16.6 & 0.1 & 16.5 & 0.3 \\
\hline 17 & 1400.C.20 & 15.3 & 0.4 & 16.3 & 0.0 & 16.5 & 0.2 & 16.4 & 0.1 \\
\hline 18 & HAP & 17.0 & 0.3 & 16.7 & 0.3 & 17.0 & 0.3 & 17.2 & 0.2 \\
\hline 19 & HAP.C.5 & 16.6 & 0.3 & 16.9 & 0.2 & 17.1 & 0.2 & 17.1 & 0.3 \\
\hline 20 & HAP.C.10 & 16.6 & 0.3 & 17.0 & 0.4 & 16.8 & 0.2 & 17.1 & 0.4 \\
\hline 21 & HAP.C.15 & 16.3 & 0.5 & 16.8 & 0.1 & 16.7 & 0.2 & 16.9 & 0.1 \\
\hline 22 & HAP.C.20 & 16.0 & 0.0 & 16.7 & 0.1 & 16.8 & 0.3 & 16.9 & 0.3 \\
\hline
\end{tabular}

${ }_{412}$ all resulting values in Table 4):

$$
\Delta^{18} O_{\text {synthetic bone-inorganic }}=\delta^{18} O_{\text {synthetic bone }}-\delta^{18} O_{\text {inorganic fraction }}
$$

${ }_{413}$ This measure is used to get a sense of whether the presence of organic material can influence $\delta^{18} \mathrm{O}_{\mathrm{phos}}$, but it 414 should be kept in mind this is not a perfect analogue for natural materials containing collagen, as is illustrated by ${ }_{415}$ the results below. Plotting this $\delta^{18} \mathrm{O}$ deviation from the inorganic fraction against amounts of added collagen in the 416 synthetic bone material confirms trends already seen in the $\% \mathrm{~N}$ results (Figure 4 ; see Figure 3 for a plot of $\% \mathrm{~N}$ ${ }_{417}$ results). For Pt4-PrepA samples, $\delta^{18} \mathrm{O}$ clearly deviates towards lower values with increasing collagen content of ${ }_{418}$ the synthetic bone. This trend tracks the substantial amounts of organic material seen in these silver phosphates ${ }_{419}$ from $\% \mathrm{~N}_{\text {phos }}$ measurements (Figure 3 ). In Pt4-PrepB samples on the other hand, $\delta^{18} \mathrm{O}$ values do not measurably ${ }_{420}$ differ from $\delta^{18} \mathrm{O}$ values of the inorganic fraction, even in synthetic bones with high amounts of collagen. This again, ${ }_{421}$ tracks the consistently low $\% \mathrm{~N}_{\text {phos }}$ measurements for all these samples. Both organic removal pretreatment methods ${ }_{422}$ also show only small deviations from $\delta^{18} \mathrm{O}$ of the inorganic fraction, particularly Pt1-PrepA $\left(\mathrm{H}_{2} \mathrm{O}_{2}\right.$ pretreatment $)$, 


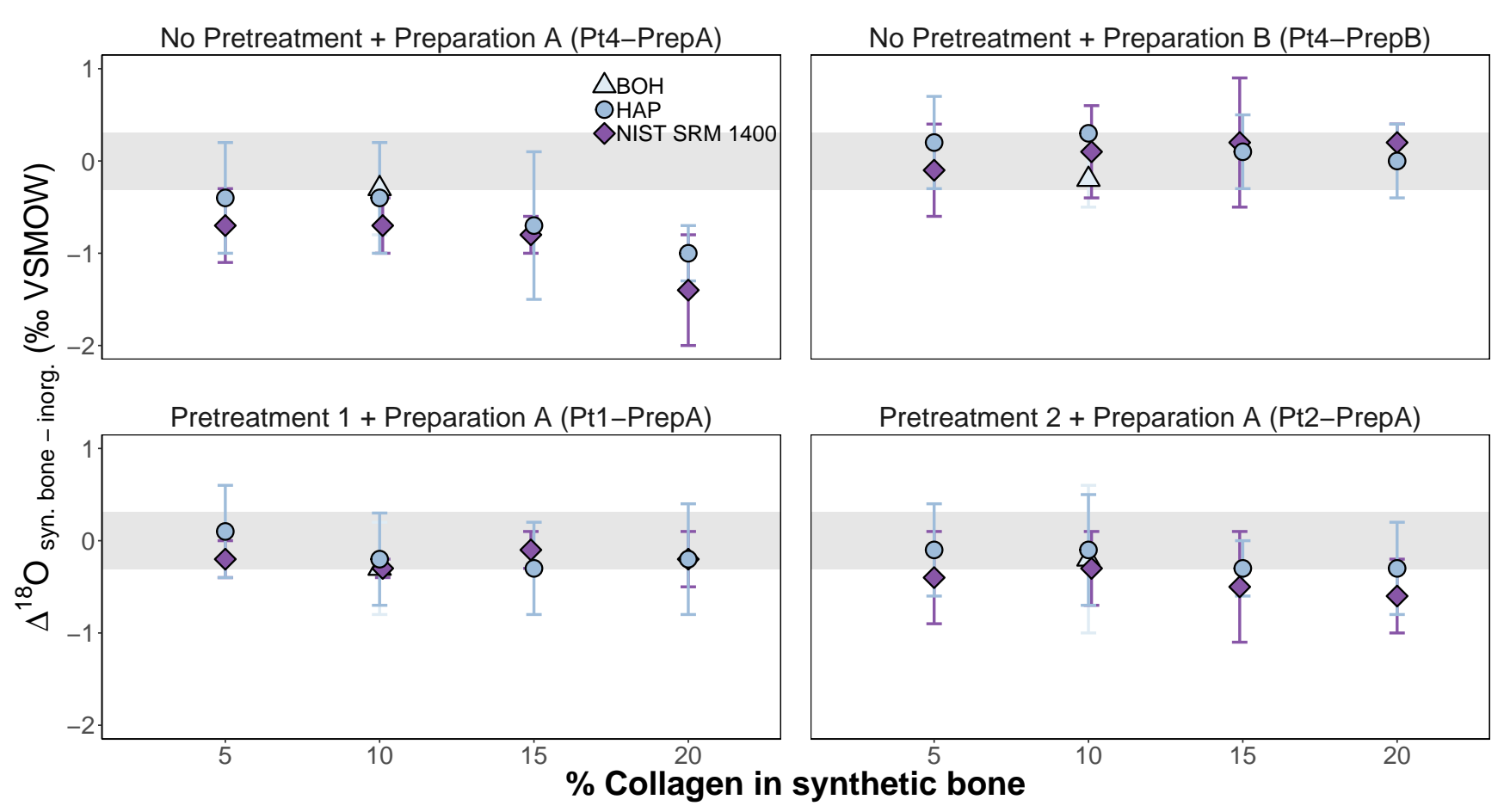

with a moderate trend towards lower $\delta^{18} \mathrm{O}$ values with high collagen content in Pt2-PrepA ( $\mathrm{NaOCl}$ pretreated) samples. However, as the removal of organic matter from synthetic bones by pretreatments does not appear to be a faithful reflection of their impact on natural bone materials (see section 3.2), these results are unlikely to generalise to pretreatment effects on actual bone samples.

Figure 4: Synthetic bone isotopic compositions (BOH: light blue triangles; HAP: blue circles; NIST SRM 1400: purple diamonds) show that $\delta^{18} \mathrm{O}$ clearly deviates towards lower values with increasing collagen content of the synthetic bone for Pt4-PrepA samples (top left) but not Pt4-PrepB samples (top right) or pretreated samples (bottom row). This mirrors the amount of organic material included in the silver phosphates of each treatment method (see Figure 3). The isotopic trends are consistent for each set of synthetic bones. Error bars represent the error of $\Delta^{18} \mathrm{O}_{\text {syn. bone - inorg }}$, derived by error propagation of the measurement uncertainty of $\delta^{18} \mathrm{O}_{\text {synn. bone }}$ and

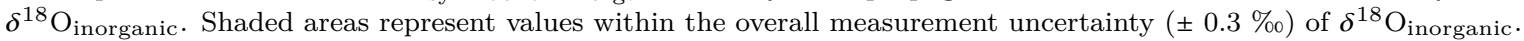

\subsubsection{Effects of preparation methods on $\delta^{18} \mathrm{O}$ in natural bones and dentine}

To explore any $\delta^{18} \mathrm{O}$ effects from the inclusion of organic material into silver phosphate in natural materials containing collagen we compare $\delta^{18} \mathrm{O}_{\text {phos }}$ between Pt4-PrepA and Pt4-PrepB for natural bone and dentine samples (Figure 5). As seen illustrated by the $\% \mathrm{~N}_{\text {phos }}$ results above, synthetic bones are not a perfect analogue to a biological bone or dentine, due to structural differences as well as differences in the isotopic offset between collagen and bioapatite phosphate. Our results show that isotopic difference of Pt4-PrepA samples from Pt4-PrepB samples $\Delta^{18} \mathrm{O}_{\mathrm{Pt4} \text {-PrepA - Pt4-PrepB }}$ ) is not solely related to the organic content of silver phosphate (as established by $\% \mathrm{~N}_{\text {phos }}$ ). Instead, we see only minimal differences between Pt4-PrepA and Pt4-PrepB values for modern bones (BRWB, WMB14B) and modern dentine (WMB14D). Isotopic deviations larger than measurement uncertainty are only seen in the two Pleistocene bones (S-EVA-2000, S-EVA-2001) and the steamed bone meal NIST SRM 1486. 
Table 4: Isotopic shifts from the isotopic composition of the inorganic fraction $\left(\Delta^{18} \mathrm{O}_{\text {syn.bone - inorg. }}\right)$ in synthetic bones for samples produced with each preparation method and samples pretreated using the organic removal pretreatments. The error of $\Delta^{18} \mathrm{O}_{\text {syn.bone - inorg. }}$ $\epsilon$, is calculated by error propagation of the measurement errors of $\Delta^{18} \mathrm{O}_{\text {syn.bone }}$ and $\Delta^{18} \mathrm{O}_{\text {inorg. }}$ Isotopic shifts larger than the commonly achieved measurement uncertainty $( \pm 0.3 \%$ ) are noted in bold.

\begin{tabular}{|c|c|c|c|c|c|c|c|c|c|}
\hline No & Sample code & $\begin{array}{l}\text { Pt4-PrepA } \\
\Delta^{18} \mathrm{O}_{\text {syn. bone - ino }}\end{array}$ & $\epsilon$ & $\begin{array}{l}\text { Pt4-PrepB } \\
\Delta^{18} \mathrm{O}_{\text {syn. bone - ino }}\end{array}$ & $\epsilon$ & $\begin{array}{l}\text { Pt1-PrepA } \\
\Delta^{18} \mathrm{O}_{\text {syn. bone - ino }}\end{array}$ & $\epsilon$ & $\begin{array}{l}\text { Pt2-PrepA } \\
\Delta^{18} \mathrm{O}_{\text {syn. bone - ino }}\end{array}$ & $\epsilon$ \\
\hline 7 & $\mathrm{BOC}$ & -0.3 & 0.5 & -0.2 & 0.3 & -0.3 & 0.5 & -0.2 & 0.8 \\
\hline 13 & 1400.C & - & 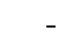 & 0.2 & 0.4 & - & - & - & - \\
\hline 14 & 1400.C.5 & -0.7 & 0.4 & -0.1 & 0.5 & -0.2 & 0.2 & -0.4 & 0.5 \\
\hline 15 & 1400.C.10 & -0.7 & 0.3 & 0.1 & 0.5 & -0.3 & 0.1 & -0.3 & 0.4 \\
\hline 16 & 1400.C.15 & -0.8 & 0.2 & 0.2 & 0.7 & -0.1 & 0.2 & -0.5 & 0.6 \\
\hline 17 & 1400.C.20 & -1.4 & 0.6 & 0.2 & 0.2 & -0.2 & 0.3 & -0.6 & 0.4 \\
\hline 19 & HAP.C.5 & -0.4 & 0.6 & 0.2 & 0.5 & 0.1 & 0.5 & -0.1 & 0.5 \\
\hline 20 & HAP.C.10 & -0.4 & 0.6 & 0.3 & 0.7 & -0.2 & 0.5 & -0.1 & 0.6 \\
\hline 21 & HAP.C.15 & -0.7 & 0.8 & 0.1 & 0.4 & -0.3 & 0.5 & -0.3 & 0.3 \\
\hline 22 & HAP.C. 20 & -1.0 & 0.3 & 0.0 & 0.4 & -0.2 & 0.6 & -0.3 & 0.5 \\
\hline- & Mean & -0.7 & 0.5 & 0.1 & 0.5 & -0.2 & 0.4 & -0.3 & 0.5 \\
\hline
\end{tabular}

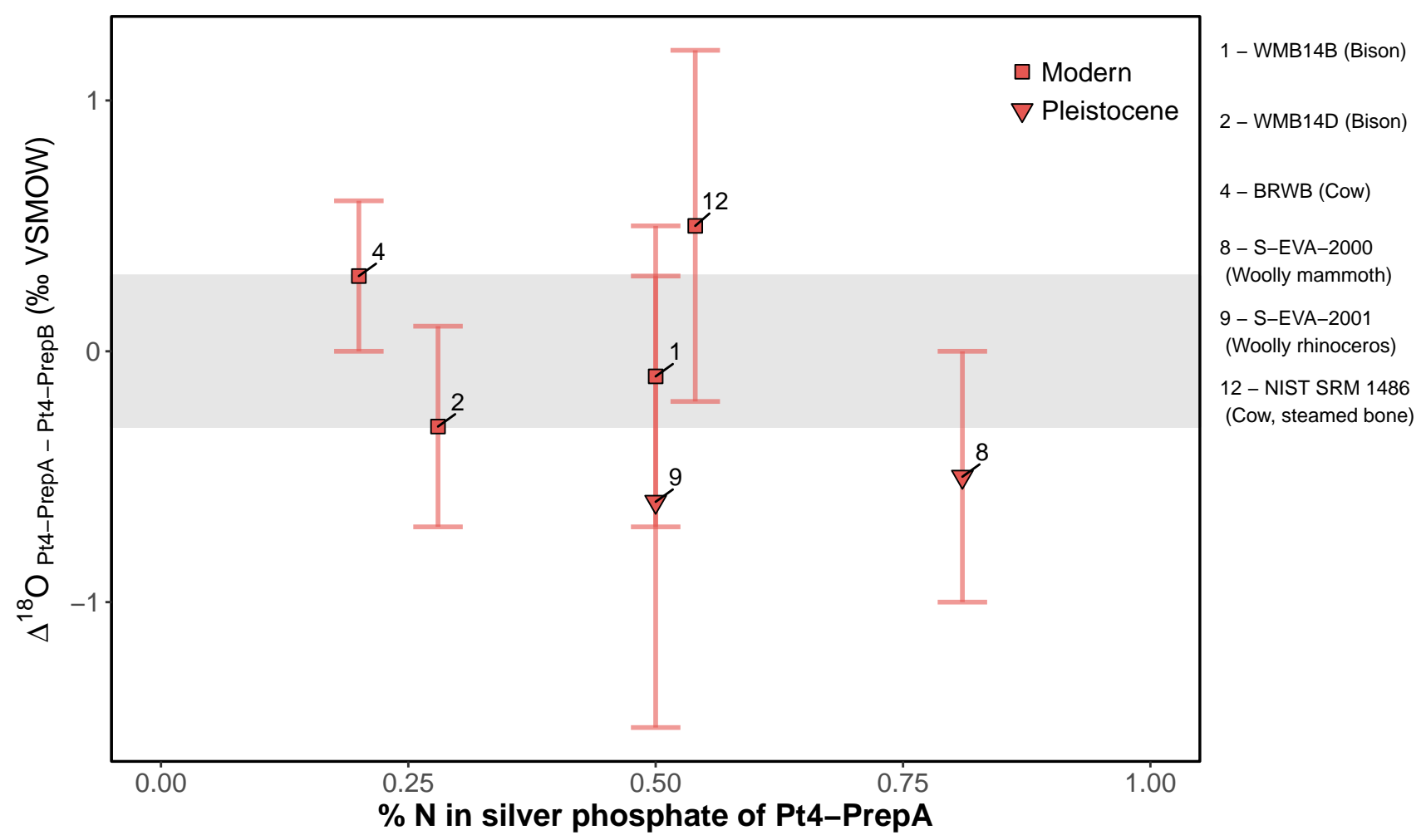

Figure 5: Isotopic difference between Pt4-PrepA samples from Pt4-PrepB ( $\Delta^{18} \mathrm{O}_{\mathrm{Pt4}}$-PrepA - Pt4-PrepB $)$ in natural biological bones and dentine shows no straightforward relationship with the organic content of silver phosphate in Pt4-PrepA samples (represented by $\% \mathrm{~N}_{\text {phos }}$ ). Presevaration state (Pleistocene samples represented by inverted triangles, modern samples represented by squares), as well as the species specific isotopic offset between collagen and bioapatite phosphate may play a role. Error bars represent the error of $\Delta^{18} \mathrm{O}_{\mathrm{Pt} 4-\mathrm{PrepA}}$ - Pt4-PrepB, derived by error propagation of the measurement uncertainty of $\delta^{18} \mathrm{O}_{\mathrm{Pt} 4-\mathrm{PrepA}}$ and $\delta^{18} \mathrm{O}_{\mathrm{Pt} 4-\mathrm{PrepB}}$ Shaded areas represent values within the overall measurement uncertainty $\left( \pm 0.3 \%\right.$ of $\delta^{18} \mathrm{O}_{\mathrm{Pt} 4-\mathrm{PrepB}}$. 
Table 5: Isotopic shifts from the Pt4-PrepB 'true' value $\left(\Delta^{18} \mathrm{O}_{\mathrm{Pt}}-\mathrm{Pt4}\right.$-PrepB $)$ in natural and standard materials pretreated with $\mathrm{H}_{2} \mathrm{O}_{2}$ (Pt1-PrepA) or NaOCl (Pt2-PrepA) organic removal pretreatments. The error of $\Delta^{18} \mathrm{O}_{\mathrm{Pt}}-\mathrm{Pt} 4$-PrepB,$\epsilon$, is calculated by error propagation of the measurement errors of $\Delta^{18} \mathrm{O}_{\mathrm{Pt}}$ and $\Delta^{18} \mathrm{O}_{\mathrm{Pt} 4-\mathrm{PrepB}}$. Isotopic shifts larger than measurement uncertainty $(0.3 \%$ ) are noted in bold.

\begin{tabular}{rlrrrr}
\hline No & Sample code & \multicolumn{2}{c}{ Pt1-PrepA } & $\epsilon$ & \multicolumn{2}{c}{ Pt2-PrepA } & $\epsilon$ \\
& & $\Delta^{18} \mathrm{O}_{\mathrm{Pt}-\mathrm{Pt} 4-\mathrm{PrepB}}$ & & $\Delta^{18} \mathrm{O}_{\mathrm{Pt}-\mathrm{Pt} 4-\mathrm{PrepB}}$ \\
\hline 1 & WMB14B & $\mathbf{- 1 . 4}$ & 0.4 & $\mathbf{- 0 . 3}$ & 0.2 \\
2 & WMB14D & $\mathbf{- 0 . 7}$ & 0.5 & $\mathbf{0 . 4}$ & 0.3 \\
3 & WMB14E & $\mathbf{0 . 3}$ & 0.5 & $\mathbf{0 . 5}$ & 0.5 \\
4 & BRWB & 0.0 & 0.2 & 0.2 & 0.3 \\
5 & BRWE & 0.1 & 0.3 & $\mathbf{0 . 4}$ & 0.5 \\
6 & BOH & $\mathbf{- 0 . 3}$ & 0.5 & $\mathbf{- 0 . 4}$ & 0.5 \\
7 & BOC & $\mathbf{- 0 . 4}$ & 0.3 & $\mathbf{- 0 . 4}$ & 0.6 \\
8 & S-EVA-2000 & $\mathbf{0 . 9}$ & 0.3 & $\mathbf{0 . 8}$ & 0.5 \\
9 & S-EVA-2001 & $\mathbf{- 0 . 4}$ & 0.9 & $\mathbf{0 . 3}$ & 0.8 \\
10 & NIST SRM 120c & -0.1 & 0.3 & $\mathbf{- 0 . 4}$ & 0.2 \\
11 & NIST SRM 1400 & $\mathbf{0 . 6}$ & 0.3 & $\mathbf{0 . 9}$ & 0.5 \\
12 & NIST SRM 1486 & 0.3 & 0.6 & $\mathbf{0 . 7}$ & 0.7 \\
18 & HAP & $\mathbf{0 . 3}$ & 0.6 & $\mathbf{0 . 5}$ & 0.5 \\
\hline- & Mean & -0.1 & 0.4 & 0.2 & 0.5 \\
\hline
\end{tabular}

\subsubsection{Effects of pretreatments on $\delta^{18} \mathrm{O}$ of inorganic materials}

To assess unwanted impacts of pretreatments on the inorganic fraction of bioapatite by $\mathrm{H}_{2} \mathrm{O}_{2}$ (Pt1-PrepA) or $\mathrm{NaOCl}$ (Pt2-PrepA) pretreatment, we compare $\delta^{18} \mathrm{O}$ values of pretreated inorganic samples to $\delta^{18} \mathrm{O}$ values Pt4-PrepB samples (Figure 6; see Table 5 for $\Delta^{18} \mathrm{O}_{\mathrm{Pt}}$ - Pt4-PrepB values). For the purposes of this study we include in the group of inorganic samples also NIST SRM 120c, which contains some organic impurities, but due to the very low amount of organic matter generally resembles much more an enamel sample rather than a bone or dentine. Except for NIST SRM 1400 (ashed bone), the deviation of pretreated samples from the Pt4-PrepB samples falls within or close to (error of the deviation overlaps) the commonly achieved measurement uncertainty $(0.3 \%$ of the unpretreated sample. Pt2-PrepA shows overall larger deviations from Pt4-PrepB for most samples. At the same time, the direction and magnitude of the deviation from Pt4-PrepB $\delta^{18} \mathrm{O}$ values does not follow a systematic pattern, but rather both pretreatments appear to have unpredictable, if mostly limited effects on $\delta^{18} \mathrm{O}$ values of inorganic materials. However, deviations from the Pt4-PrepB $\delta^{18} \mathrm{O}$ value can be as large as $0.9 \%$ ofor samples pretreated with $\mathrm{NaOCl}$. 


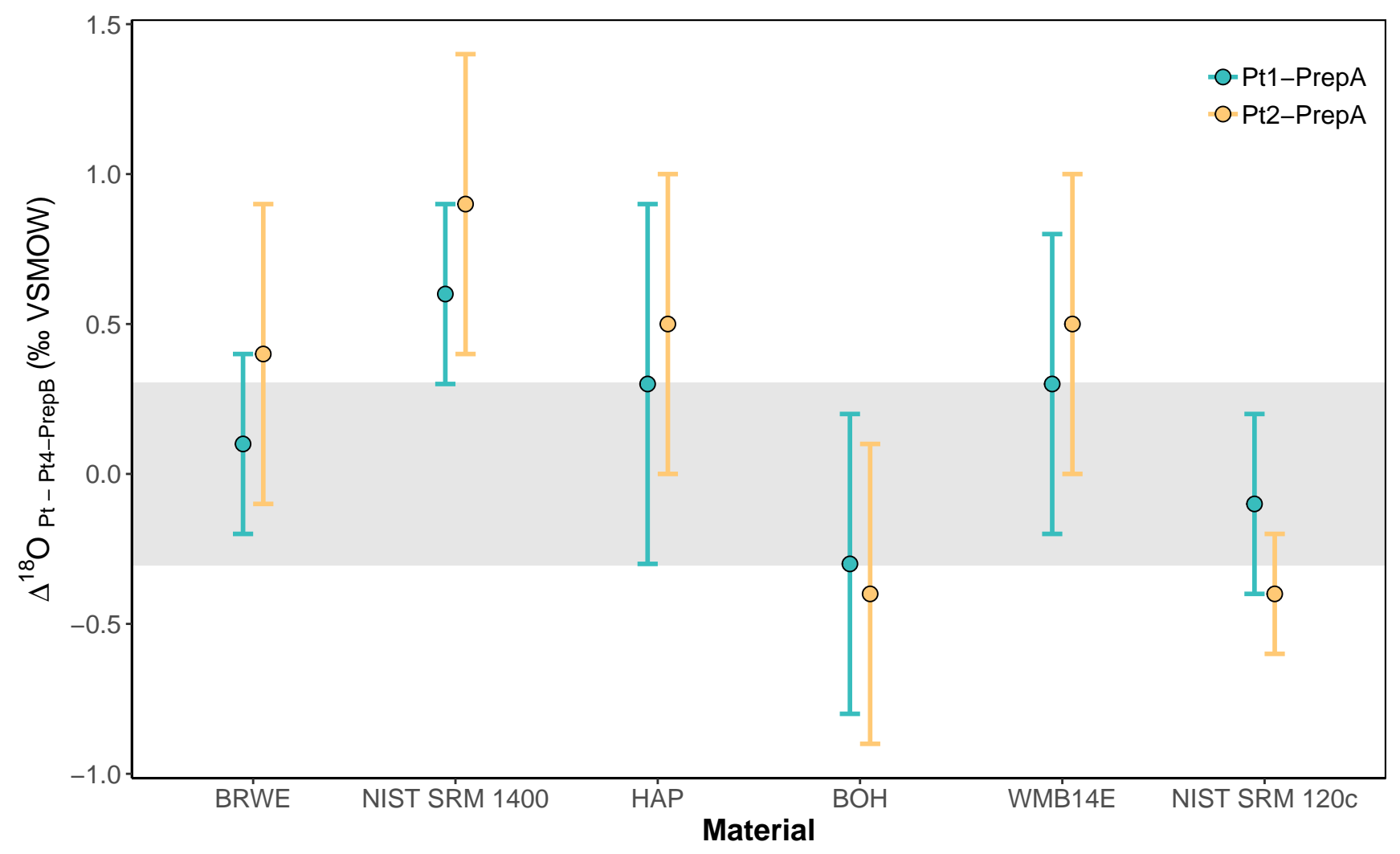

Figure 6: For inorganic materials both $\mathrm{H}_{2} \mathrm{O}_{2}$ (Pt1-PrepA, green) and especially NaOCl (Pt2-PrepA, yellow) pretreatments show detrimental impacts on sample $\delta^{18} \mathrm{O}$. The magnitude of isotopic shifts (representend by $\Delta^{18} \mathrm{O}_{\mathrm{Pt}}$ - Pt4-PrepB) or their direction is not correlated with the isotopic composition of the sample (materials orderded by $\delta^{18} \mathrm{O}$ from lowest (left) to highest (right)). Error bars represent the error of $\Delta^{18} \mathrm{O}_{\mathrm{Pt}}-\mathrm{Pt4}$-PrepB, derived by error propagation of the measurement uncertainty of $\delta^{18} \mathrm{O}_{\mathrm{Pt}}$ and $\delta^{18} \mathrm{O}_{\mathrm{Pt} 4-\mathrm{PrepB}}$. Shaded areas represent values within the overall measurement uncertainty $\left( \pm 0.3 \%\right.$ of $\delta^{18} \mathrm{O}_{\mathrm{Pt} 4-\mathrm{PrepB}}$.

\subsubsection{Effects of pretreatments on $\delta^{18} \mathrm{O}$ of natural bones and dentine}

To assess impacts of pretreatments on natural bone and dentine samples by either Pt1-PrepA or Pt2-PrepA, we compare $\delta^{18} \mathrm{O}$ values of silver phosphate precipitates from pretreated bone and dentine samples to $\delta^{18} \mathrm{O}$ values of Pt4PrepB samples in dependence of bone/dentine collagen content and age (Figure 7; see Table 5 for $\Delta^{18} \mathrm{O}_{\mathrm{Pt}}$ - Pt4-PrepB values). Modern bones and dentine mostly show $\delta^{18} \mathrm{O}$ deviations towards lower $\delta^{18} \mathrm{O}$ values with increasing collagen content. In archaeological bones on the other hand, the two samples analysed here do not fit with the trend observed in modern bones and dentine. This may point to an influence of bone preservation on pretreatment effects, but, as only two archaeological bones were analysed, the small sample size must be borne in mind. Larger $\delta^{18} \mathrm{O}$ deviation in high collagen modern bones is particularly pronounced for Pt1-PrepA $\left(\mathrm{H}_{2} \mathrm{O}_{2}\right.$ pretreated) samples. In Pt2-PrepA ( $\mathrm{NaOCl}$ pretreated) samples, the deviation from Pt4-PrepB samples is small and within or close to measurement uncertainty, while Pt1-PrepA samples often substantially diverge from Pt4-PrepB samples by up to -1.4 \%o. 


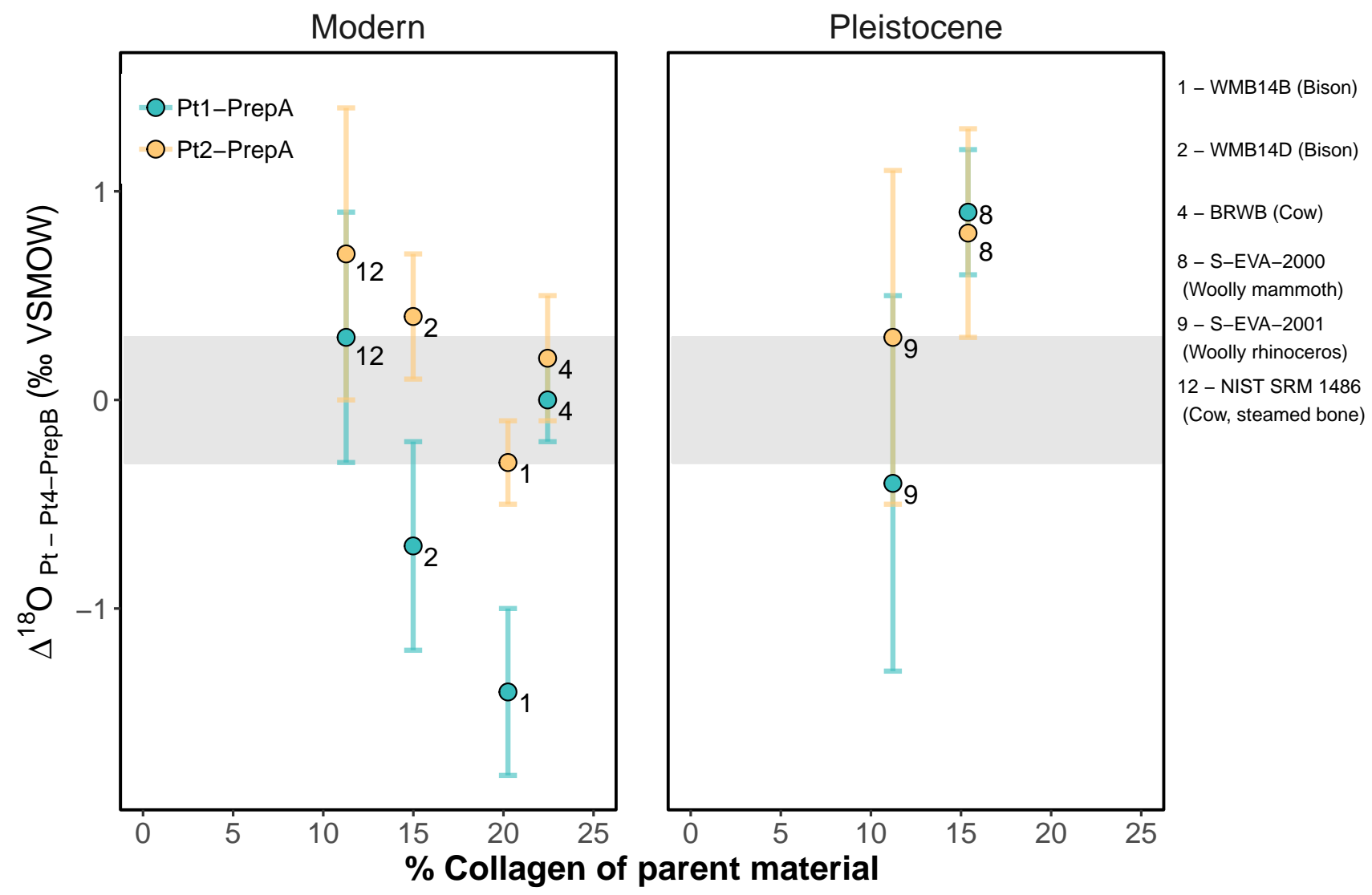

Figure 7: Both $\mathrm{H}_{2} \mathrm{O}_{2}$ (Pt1-PrepA, green) and NaOCl (Pt2-PrepA, yellow) pretreatments shift sample $\delta^{18} \mathrm{O}$ from its true value. These shifts show different trends with collagen content of the parent material for modern materials (left) compared to Pleistocene bones (right). Error bars represent the error of $\Delta^{18} \mathrm{O}_{\mathrm{Pt}}$ - Pt4-PrepB, derived by error propagation of the measurement uncertainty of $\delta^{18} \mathrm{O}_{\mathrm{Pt}}$ and $\delta^{18} \mathrm{O}_{\mathrm{Pt} 4-\mathrm{PrepB}}$. Shaded areas represent values within the overall measurement uncertainty $\left( \pm 0.3 \%\right.$ of $\delta^{18} \mathrm{O}_{\mathrm{Pt} 4-\mathrm{PrepB}}$.

\section{Discussion}

\subsection{Pt3: Nitric acid pre-dissolution}

Concerns about interference of the organic matrix of bones with the complete dissolution of the bioapatite fraction were originally raised by O'Neil et al. (1994), due to long dissolution times observed in chunk bone samples. O'Neil et al. (1994) therefore proposed a pre-dissolution in nitric acid to avoid fractionation effects caused by incomplete dissolution. However, FTIR spectra of $\mathrm{CaF}_{2}$ precipitates from the dissolution of modern bone and hydroxyapatite show no traces of bioapatite in the precipitate (Figure 2) above a detection limit corresponding to a bioapatite mass loss of ca. $1 \%$ in a $10 \mathrm{mg}$ sample. Additionally, there appears to be no difference between $\mathrm{HNO}_{3}$ predissolved bone samples and untreated samples directly dissolved in $\mathrm{HF}$ or between $\mathrm{CaF}_{2}$ of bone samples and $\mathrm{CaF}_{2}$ from commercial hydroxyaptite. This indicates that any inhibition of bioapatite dissolution by the organic matrix is minimal. This is underlined by $\mathrm{CaF}_{2}$ yields, which consistently conform to stoichiometric expectation for all untreated samples and we see no difference in $\mathrm{CaF}_{2}$ recovery between bone samples and inorganic samples. This 
suggests that the presence of organic matter has negligible influence on the $\mathrm{CaF}_{2}$ formation and sample dissolution process. Slightly lower silver phosphate yields for $\mathrm{HNO}_{3}$ pre-dissolved WMB14B samples compared to unpretreated samples shows that this pretreatment does not lead to more efficient sample dissolution. It therefore seems likely that problems with dissolution observed by O'Neil et al. (1994) were mostly due to the use of bone chunks as well as large (> $30 \mathrm{mg}$ ) samples sizes. Based on our results we suggest that using powdered samples with a sample size of $10 \mathrm{mg}$ or less is sufficient to ensure complete dissolution of bioapatite, even in the presence of substantial amounts of organic material (e.g. modern bone).

\subsection{Pt4-PrepA: rapid precipitation without anion exchange purification}

Our results indicate that Pt4-PrepA (rapid precipitation of silver phosphate without prior anion exchange purification) can lead to the inclusion of substantial amounts of organic material in the silver phosphate product (Figure 3), and routinely exceeds thresholds likely to indicate isotopically 'problematic' levels of organic contamination (see section 2.6 for how this threshold is dertermined). This amount of organic contamination is mostly determined by the amount of collagen present in the original sample, but, archaeological bones with only moderate collagen content can show higher $\% \mathrm{~N}$ values than very organic-rich modern bones, underlining that collagen preservation state is also an important consideration. Oxygen isotopic analyses of synthetic bones demonstrate that organic contamination detected by $\% \mathrm{~N}$ measurements has the potential to lead to substantial bias in $\delta^{18} \mathrm{O}$ values towards much lower $\delta^{18} \mathrm{O}$ values than expected (Figure 4). It should be noted, however, that the specific magnitude of deviation in $\delta^{18} \mathrm{O}$ values from the expected value depends on the specific isotopic composition of the bone collagen: due to this, the specific magnitude of the isotopic shift measured in synthetic bones here will not translate exactly into natural bone materials. However, the isotopic impact of organic inclusions in silver phosphate precipitates from the natural materials utilised in this study on their measured $\delta^{18} \mathrm{O}$ values is more complex to discern. While $\delta^{18} \mathrm{O}$ values of precipitates derived from organic-rich modern bone and dentine (WMB14B and WM14D) prepared using Pt4-PrepA and Pt4-PrepB differ only very marginally (and within error), the measured $\delta^{18} \mathrm{O}$ values of archaeological (Pleistocene) bones as well as of the steam treated NIST SRM 1486 prepared using the two different protocols differed more vastly. Some of this variation might be explained by differences between samples in their isotopic offset between collagen and bioapatite phosphate, which is likely species specific. At the same time, bone preservation state remains an additional concern, as diagenesis of bone collagen or the mineral matrix could potentially cause shifts either in the isotopic difference between collagen and bioapatite phosphate, or alter the chemical composition of collagen leading to variability in the isotopic impact of collagen contamination. The role of biological and/or diagenetic variability in the collagen/mineral isotopic offset is highlighted by the fact that Pt4-PrepA samples of S-EVA-2001 (archaeological woolly rhinoceros bone) shows a considerably larger isotopic deviation from the Pt4-PrepB than Pt4-PrepA samples of WMB14B (modern bison bone), despite being equivalent in $\% \mathrm{~N}_{\text {phos }}$. Considering the small sample size of natural bones, and particularly of archaeological bones, used here it is difficult to determine the exact mechanism behind this stronger isotopic deviation in archaeological samples. While species specific isotopic offsets, 
collagen preservation and diagenetic changes to $\delta^{18} \mathrm{O}$ values of collagen may influence how collagen contamination of silver phosphate impacts $\delta^{18} \mathrm{O}_{\text {phos }}$ values, it is also plausible that contamination with humic substances or an altogether different aspect may be at play. Further studies on samples with a known isotopic offset between collagen and bioapatite phosphate, as well as more work into potential diagenetic impacts on $\delta^{18} \mathrm{O}$ of collagen is needed to shed more light into this issue. However, due to impacts of collagen extraction methods on $\delta^{18} \mathrm{O}$ of collagen (von Holstein et al., 2018), biological $\delta^{18} \mathrm{O}$ values may be challenging to determine for such work.

At the same time, the presence of substantial amounts of nitrogen could also induce artificially lowered $\delta^{18} \mathrm{O}_{\mathrm{phos}}$ values to be measured due to the isobaric interference of $\mathrm{N}_{2}$ and the sample gas $\mathrm{CO}$. Issues of this kind have been reported for a number of nitrogen containing organic sample substrates such as plants or keratins (e.g. Qi et al., 2011; Farquhar et al., 1997), where the high amount of nitrogen in samples can lead to imperfect gas separation by the standard $0.6 \mathrm{~m}$ GC column set up routinely employed in TC/EA type instruments. Imperfect separation of the $\mathrm{N}_{2}$ and $\mathrm{CO}$ peaks would lead to lowered $\delta^{18} \mathrm{O}_{\text {phos }}$ values in samples containing organic matter and could technically be responsible for the trends we observe in our results, particularly in synthetic bones. However, several points suggest that any $\mathrm{N}_{2}$ isobaric interference was negligible in our study. Firstly, sample substrates that have been shown to suffer from this issue commonly exhibit much higher nitrogen content and nitrogen to oxygen ratio than any of the samples in the current study. For instance, substrates like caffeine of keratins have N/O ratios of 1.8 and 0.7 respectively. In our study the sample with the highest nitrogen content (WMB14B) had and N/O ratio of only 0.06, more than a factor 10 lower than what is commonly known to cause any issues during analysis. However, in oder to dtermine whether nitrogen isobaric interference could have playerd a role in our measurements, we compared $\delta^{18} \mathrm{O}$ values obtained from $\mathrm{m} / \mathrm{z} 28$ peak integration with $\delta^{18} \mathrm{O}$ values obtained from $\mathrm{m} / \mathrm{z} 30$ peak integration following Qi et al. (2011). In cases where $\mathrm{N}_{2}$ and $\mathrm{CO}$ peaks are sufficiently separated, these values should be very similar, while discrepancies might indicate isobaric interference.In our study, even for the sample with the highest nitrogen content we obtain essentially identical $\delta^{18} \mathrm{O}$ values fro the two integration methods (21.61 and $21.62 \%$ orespectively), demonstrating that $\mathrm{N}_{2}$ and $\mathrm{CO}$ were sufficiently separated to exclude $\mathrm{N}_{2}$ isobaric interference as a major driver of patterns observed in our results.

both the very low amount of nitrogen in our samples (N/O ratio at least a factor 10 lower than in reportedly problematic sample types such as keratins) and virtually identical $\delta^{18} \mathrm{O}$ values obtained from $\mathrm{m} / \mathrm{z} 28$ peak integration compared with $\delta^{18} \mathrm{O}$ values obtained from m/z 30 integration (following Qi et al. (2011)) strongly suggest that $\mathrm{N}_{2}$ and $\mathrm{CO}$ were sufficiently separated to exclude $\mathrm{N}_{2}$ isobaric interference as a major driver of our result patterns. While issues with unkown collagen/mineral isotopic offsets make it difficult to determine whether organic contamination necessarily poses an issue for faithful $\delta^{18} \mathrm{O}_{\text {phos }}$ measurements, and if so in which amounts, we conclude that the rapid precipitation protocol without anion exchange purification cannot exclude problems related to organic contamination. For archaeological samples where organic contamination is likely to be a concern, such as bone or dentine, researchers may wish to instead use an anion exchange based protocol, which consistently eliminates the 
inclusion of organic material in silver phosphate (see discussion below).

However, due to the very low amount of organic material present in tooth enamel and the low $\% \mathrm{~N}$ value in silver phosphate prepared from modern enamel (0.1\%) a rapid precipitation protocol (without anion exchange purification) remains a time-efficient and effective option for processing enamel samples without the need for organic removal pretreatments. Similar results were obtained by Grimes and Pellegrini (2013), where \% $\mathrm{N}$ was below detection limit for silver phosphate from tooth enamel prepared using a slow precipitation protocol without anion exchange purification. Researchers may wish to still opt for a slow precipitation protocol due to advantages of slowly crystallised silver phosphate regarding reduced potential for water adsorption and easier handling, but purely regarding the potential of organic contamination the two protocols appear to be equivalent for tooth enamel samples.

\subsection{Pt4-PrepB: slow precipitation with anion exchange purification}

In contrast to Pt4-PrepA, a slow precipitation protocol with anion exchange purification (Pt4-PrepB) appears to consistently eliminate organic contamination of silver phosphate. Using this protocol the inclusion of organic material is effectively reduced to very low amounts even in silver phosphates from bones with high collagen content (Figure 3). Additionally, synthetic bones with added collagen show no bias towards lower $\delta^{18} \mathrm{O}$ values (Figure 4). On this basis we propose that the anion exchange step in this protocol effectively prevents the inclusion of organic material into the final silver phosphate and precludes the need for additional pretreatments that could ultimately affect $\delta^{18} \mathrm{O}$ values. While this study does not directly assess the effect of anion exchange purification while using the same precipitation method, \%N data from Grimes and Pellegrini (2013) shows high \%N values (1.8\%) in silver phosphates from bone samples prepared using a slow precipitation without anion exchange purification. This suggests that anion exchange is the key factor to producing contamination free silver phosphate while the precipitation method plays only a minor role. While organic contamination does not always lead to biased $\delta^{18} \mathrm{O}_{\text {phos values (see section }}$ 4.2), we see the use of anion exchange purification as the 'safest' option for treating organic-rich samples to prevent issues related to the inclusion of organic material, whether a rapid or slow precipitation is employed. Explicit testing to combine anion exchange purification with a rapid precipitation technique are beyond the scope of this study, but we expect that further work on this could yield a more time efficient version of the robust protocol identified in this study and we welcome future investigations of this aspect in particular.

There has previously been sporadic concern about introduction of organic contamination by the anion exchange resin Amberlite based on the green tinged colour of silver phosphates produced from methods using this resin (e.g. Crowson et al., 1991; Stephan, 2000). Our \%N results do not suggest that organic material is introduced by the anion exchange resin used in this study. This may indicate that crystal colour is not be a good indicator of the amount of organic material included in silver phosphate, as has been previously noted by Grimes and Pellegrini (2013).

Due to the effective prevention of organic contamination in samples produced using the Pt4-PrepB method, the $\delta^{18} \mathrm{O}$ values measured on these samples will be considered as coming the closest to the true $\delta^{18} \mathrm{O}$ value of the 
inorganic fraction in the following evaluation of the pretreatment methods.

\subsection{Pt1-PrepA: Hydrogen peroxide}

Confirming previous results (e.g. Lécuyer, 2004; Grimes and Pellegrini, 2013; Snoeck and Pellegrini, 2015) our study shows $\mathrm{H}_{2} \mathrm{O}_{2}$ pretreatment (Pt1-PrepA) to be only moderately effective at reducing the organic contamination included in silver phosphate (Figure 3). This pretreatment method only appears fully successful in removing organic material from synthetic bones, where collagen is not chemically bound to the mineral portion of the sample, while a substantial amount of organic material is transferred into silver phosphates in natural bone samples. This means that even though $\delta^{18} \mathrm{O}$ values of synthetic bones show no bias from organic contamination, this result is unlikely to translate into natural bone materials. A $30 \% \mathrm{H}_{2} \mathrm{O}_{2}$ pretreatment is therefore not suitable for producing silver phosphates that are reliably free from organic contamination from bone or dentine samples.

However, the impact of this pretreatment on $\delta^{18} \mathrm{O}$ values of silver phosphate precipitates is not systematic in direction or magnitude, and is often minor (Figure 6). Grimes and Pellegrini (2013) on the other hand observed consistent positive offsets in $\delta^{18} \mathrm{O}$ caused by the $\mathrm{H}_{2} \mathrm{O}_{2}$ pretreatment. This discrepancy between our results and Grimes and Pellegrini (2013) is likely due to the larger set of samples used in this study. The differences in methodology between the studies is not expected to affect results in this particular instance, as neither precipitation method nor resin use should have an impact on $\delta^{18} \mathrm{O}$ values of mostly inorganic samples (O'Neil et al., 1994; Dettman et al., 2001; Lécuyer, 2004).

In natural bone materials on the other hand, deviations from Pt4-PrepB values are more pronounced, although we notice different behaviours in modern compared to archaeological bones (Figure 7). In modern bones considerably lower $\delta^{18} \mathrm{O}$ values than the Pt4-PrepB value most likely reflects bias towards lower $\delta^{18} \mathrm{O}$ values caused by residual organic contamination, as $\% \mathrm{~N}$ measurements have shown that the pretreatment is not effective at removing organic material from these samples. Confoundingly, in archaeological bones $\delta^{18} \mathrm{O}$ values are substantially higher than Pt4-PrepB values (Figure 7), a result also observed by Grimes and Pellegrini (2013). This indicates that $\mathrm{H}_{2} \mathrm{O}_{2}$ may have adverse effects on $\delta^{18} \mathrm{O}$ of the mineral fraction in archaeological bones, which may be more vulnerable to chemical changes than pristine modern materials or more highly crystalline inorganic materials. Grimes and Pellegrini (2013) suggests that oxygen exchange between $\mathrm{H}_{2} \mathrm{O}_{2}$ and bioapatite phosphate may cause $\delta^{18} \mathrm{O}$ changes in bioapatite, based on a systematic rise of $\delta^{18} \mathrm{O}$ values following this pretreatment. However, our results indicate that this mechanism is not sufficient to explain the observed effects given more data that disrupt the systematic pattern observed by Grimes and Pellegrini. If only oxygen exchange was taking place, inorganic samples pretreated with $\mathrm{H}_{2} \mathrm{O}_{2}$ should show $\delta^{18} \mathrm{O}$ changes whose direction and magnitude is dependent on the isotopic composition of the sample. For instance, a sample with a $\delta^{18} \mathrm{O}$ value close to that of $\mathrm{H}_{2} \mathrm{O}_{2}$, which has been measured at $23.8 \%$ in dissociation experiments (Barnette et al., 2011), should show small changes, while a sample with a $\delta^{18} \mathrm{O}$ value that is much lower than that of $\mathrm{H}_{2} \mathrm{O}_{2}$ should show a stronger $\delta^{18} \mathrm{O}$ shift towards higher values. As we do not observe such a pattern (Figure 6), other mechanisms appear to influence the effect of $\mathrm{H}_{2} \mathrm{O}_{2}$ pretreatment on the pristine isotopic 
composition of bioapatite phosphate. Unfortunately the larger yet still small sample size of this study does not allow

further inference on the exact mechanism that drives such isotopic changes, although the nature of the sample, its collagen content, age and preservation state are likely factors in influencing how samples respond to pretreatment.

Despite the variable effects observed, including differences between modern and archaeological bones, the possibility of adverse effects on $\delta^{18} \mathrm{O}$ values and only moderate effectiveness in preventing organic contamination mean that this pretreatment overall is not recommended for use with bone samples. Based on the limited effect on purely inorganic materials observed here, this pretreatment may be less problematic for use with tooth enamel. However, in light of the fact that organic contamination from enamel proteins appears to be very limited even in unpretreated samples, and that organic material inclusion can also be prevented using anion exchange purification, use of a pretreatment seems an unnecessary risk.

\subsection{Pt2-PrepA: Sodium hypochlorite}

Our results as well as previous work (Stephan, 2000; Grimes and Pellegrini, 2013; Snoeck and Pellegrini, 2015; Shabaga et al., 2018) shows that even relatively low concentration bleach pretreatment is more effective than $\mathrm{H}_{2} \mathrm{O}_{2}$ at removing organic material from bones, even those with high collagen content (Figure 3). This means that, in contrast to $\mathrm{H}_{2} \mathrm{O}_{2}$ pretreatment, the bleach pretreatment can reliably oxidise organic material that is protected by the bond with the mineral matrix. This pretreatment is therefore more suited to producing organic free silver phosphates from bone samples.

However, the bleach pretreatment may also incur unintended effects on $\delta^{18} \mathrm{O}$ of the mineral fraction of the sample which - in many cases - were more pronounced than those impacts from the $\mathrm{H}_{2} \mathrm{O}_{2}$ pretreatment. Indeed, in purely inorganic samples we see considerably larger $\delta^{18} \mathrm{O}$ deviations from the 'true' Pt4-PrepB values than for the $\mathrm{H}_{2} \mathrm{O}_{2}$ pretreatment (Figure 6). As there is almost no organic material present in these samples, this means that the pretreatment also causes some isotopic changes in the mineral phase of the samples used here. These changes in $\delta^{18} \mathrm{O}$ values are inconsistent in both direction and magnitude and independent of $\delta^{18} \mathrm{O}$ value of the sample, so a specific cause behind these changes is hard to pinpoint.

In natural bones and dentine we also observe some changes in $\delta^{18} \mathrm{O}$ compared to the Pt4-PrepB values (Figure 7). In modern bones, samples with elevated collagen content give values within measurement uncertainty of the Pt4-PrepB value, which indicates that the efficient removal of organic material by the bleach treatment has some mitigating effect on $\delta^{18} \mathrm{O}$ shifts from organic contamination. However, at the same time $\delta^{18} \mathrm{O}$ values in lower collagen bones that are substantially higher than the Pt4-PrepB value indicate that some undesired side effects act on the isotopic composition of these samples. From our samples it appears that the collagen content of bone moderates the effect of the pretreatment and the extent of its side effects. Possibly, the mineral matrix is more vulnerable to chemical attack by the pretreatment agent if only moderate amounts of collagen are present to 'absorb' the effects of the bleach. Such a mechanism could also explain $\delta^{18} \mathrm{O}$ offsets in archaeological bones towards higher $\delta^{18} \mathrm{O}$ values in 
bleach pretreated bones. As these bones have only a moderate collagen content and are less well preserved than fresh bones, their mineral fraction may be more susceptible to attack by $\mathrm{NaOCl}$ resulting in artificially high $\delta^{18} \mathrm{O}$ values.

Overall our results suggest that while $\mathrm{NaOCl}$ is a more effective organic removal agent (compared to $\mathrm{H}_{2} \mathrm{O}_{2}$ ), it has more pronounced undesirable side effects on the pristine isotopic composition of bioapatite phosphate. Compared to treatment with $\mathrm{H}_{2} \mathrm{O}_{2}$ these side effects can be quite substantial (up to $1.9 \%$ ), even for the low concentration of $\mathrm{NaOCl}$ used in this study. This pretreatment is therefore likely to be an unreliable approach for obtaining biogenic $\delta^{18} \mathrm{O}$ values from either bone or tooth samples, and should be avoided.

\section{Conclusion}

Our observations show that use of an anion exchange purification step during silver phosphate preparation leads to the production of pure silver phosphate that are consistently free of organic contamination. Use of this protocol mitigates bias towards lower $\delta^{18} \mathrm{O}$ values that may be caused by the presence of organic material. While not tested here, anion exchange purification could then be successfully combined with either a a slow or a rapid precipitation protocol in archaeological and palaeontological studies concerned with organic contamination. Our results also confirm that incomplete dissolution of bioapatite in the presence of organic material does not appear to be an issue in powdered samples. A rapid precipitation protocol without anion exchange purification, on the other hand, can lead to the inclusion of substantial amounts of organic material in silver phosphate made from bone. However, based in the bone samples studied here, inclusion of organic material does not always necessarily cause isotopic shifts larger than measurement uncertainty. Whether organic contamination impacts $\delta^{18} \mathrm{O}_{\text {phos }}$ measurements appears not only to depend on the amount of organic material included, but also the species specific isotopic offset between collagen oxygen and bioapatite phosphate oxygen and possibly on other factors. Diagenetic changes to $\delta^{18} \mathrm{O}$ values of collagen, and changes to the mineral matrix, along with the inclusion of non-collagenous organic molecules may be important factors to consider, but further study is needed to elucidate such mechanisms. Nonetheless, as biased $\delta^{18} \mathrm{O}$ results can occur for contaminated silver phosphates we recommend use of an anion exchange based protocol for processing of organic-rich bioapatite samples as the 'safest' option. However, our results do show that tooth enamel samples can still be processed effectively with a rapid precipitation protocol without anion exchange purification, as they contain only trace amounts of proteins. Regarding the use of organic removal pretreatments, our results reinforce conclusions from previous studies that have demonstrated side effects of common organic removal pretreatments which can alter measured $\delta^{18} \mathrm{O}$ values: this is particularly the case for the more aggressive $\mathrm{NaOCl}$. While $\mathrm{H}_{2} \mathrm{O}_{2}$ pretreatment appears less prone to cause $\delta^{18} \mathrm{O}$ shifts to the inorganic fraction, it is only partially effective at removing organic material. Considering that anion exchange purification is shown here to be as effective as $\mathrm{NaOCl}$ in preventing organic contamination, but without any observable side effects on the isotopic composition of bioapatite phosphate, we would therefore conclude that this protocol is to be preferred over a pretreatment based approach, especially for samples that are rich in organic material, such as bone. 


\section{Acknowledgements}

The authors would like to thank Wolfram Meier-Augenstein (Robert Gordon University) for advice on TC/EAIRMS and to Raquel Maria (Kimmel Center for Archaeological Science, Weizmann Institute of Science) for advice on FTIR-ATR. Thanks to Birke Brumme (MPI EVA) for practical support with sample preparation. Thanks are also due to Sahra Talamo (MPI EVA/University of Bologna) for providing aliquots of the S-EVA-2000 and S-EVA-2001 in-house bone standards and to Klervia Jaouen (MPI EVA/Géosciences Environnment Toulouse) for providing extracted collagen used in the preparation of synthetic bones. This research was funded by the Max-Planck-Society as part of SP's doctoral research. The authors would also like to thank the Max-Planck-Society, the University of Aberdeen and the Vreije Universiteit Brussels for professional and financial support during the production of this manuscript. CS thanks the Research Foundation - Flanders for his post-doctoral fellowship. We also thank Christophe Lécuyer and an anonymous reviewer for their valuable comments and suggestions.

\section{References}

Allaire J., Cheng J., Xie Y., McPherson J., Chang W., Allen J. and Hyndman R. (2018) rmarkdown: Dynamic documents for $\mathrm{R}$ ( $\mathrm{R}$ package version 1.0).

Amiot R., Angst D., Legendre S., Buffetaut E., Fourel F., Adolfssen J., André A., Bojar A. V., Canoville A., Barral A., Goedert J., Halas S., Kusuhashi N., Pestchevitskaya E., Rey K., Royer A., Saraiva A. Á. F., Savary-Sismondini B., Siméon J.-L., Touzeau A., Zhou Z. and Lécuyer C. (2017) Oxygen isotope fractionation between bird bone phosphate and drinking water. The Science of Nature 104, 47.

Arppe L. M. and Karhu J. A. (2006) Implications for the Late Pleistocene climate in Finland and adjacent areas from the isotopic composition of mammoth skeletal remains. Palaeogeography, Palaeoclimatology, Palaeoecology 231, $322-330$.

Barnette J. E., Lott M. J., Howa J. D., Podlesak D. W. and Ehleringer J. R. (2011) Hydrogen and oxygen isotope values in hydrogen peroxide. Rapid Communications in Mass Spectrometry 25, 1422-1428.

Brand W. A., Coplen T. B., Aerts-Bijma A. T., Böhlke J. K., Gehre M., Geilmann H., Gröning M., Jansen H. G., Meijer H. A., Mroczkowski S. J., Qi H., Soergel K., Stuart-Williams H., Weise S. M. and Werner R. A. (2009) Comprehensive inter-laboratory calibration of reference materials for $\delta^{18} \mathrm{O}$ versus VSMOW using various on-line high-temperature conversion techniques. Rapid Communications in Mass Spectrometry 23, 999-1019.

Britton K., Fuller B. T., Tütken T., Mays S. and Richards M. P. (2015) Oxygen isotope analysis of human bone phosphate evidences weaning age in archaeological populations. American Journal of Physical Anthropology 157, $226-241$.

Bryant J. D., Luz B. and Froelich P. N. (1994) Oxygen isotopic composition of fossil horse tooth phosphate as a record of continental paleoclimate. Palaeogeography, Palaeoclimatology, Palaeoecology 107, 303-316. 
Cerling T. E. and Harris J. M. (1999) Carbon isotope fractionation between diet and bioapatite in ungulate mammals and implications for ecological and paleoecological studies. Oecologia 120, 347-363.

Colleter R., Clavel B., Pietrzak A., Duchesne S., Schmitt L., Richards M. P., Telmon N., Crubézy É. and Jaouen K. (2017) Social status in late medieval and early modern Brittany: insights from stable isotope analysis. Archaeological and Anthropological Sciences, 1-15.

Cormie A. B., Luz B. and Schwarcz H. P. (1994) Relationship between the hydrogen and oxygen isotopes of deer bone and their use in the estimation of relative humidity. Geochimica et Cosmochimica Acta 58, 3439-3449.

Crowley B. E. and Wheatley P. V. (2014) To bleach or not to bleach? Comparing treatment methods for isolating biogenic carbonate. Chemical Geology 381, 234-242.

Crowson R. A., Showers W. J., Wright E. K. and Hoering T. C. (1991) Preparation of phosphate samples for oxygen isotope analysis. Analytical Chemistry 93, 2397-2400.

Daux V., Lécuyer C., Héran M. A., Amiot R., Simon L., Fourel F., Martineau F., Lynnerup N., Reychler H. and Escarguel G. (2008) Oxygen isotope fractionation between human phosphate and water revisited. Journal of Human Evolution 55, 1138-1147.

Delgado Huertas A., Iacumin P., Stenni B., Sánchez Chillón B. and Longinelli A. (1995) Oxygen isotope variations of phosphate in mammalian bone and tooth enamel. Geochimica et Cosmochimica Acta 59, 4299-4305.

Dettman D. L., Kohn M. J., Quade J., Ryerson F. J., Ojha T. P. and Hamidullah S. (2001) Seasonal stable isotope evidence for a strong Asian monsoon., 31-34.

Eastoe J. (1979) Enamel Protein Chemistry - Past, Present and Future. Journal of Dental Research 58, 753-764.

Farquhar G. D., Henry B. K. and Styles J. M. (1997) A rapid on-line technique for determination of oxygen isotope composition of nitrogen-containing organic matter and water. Rapid Communications in Mass Spectrometry 11, 1554-1560.

Firsching F. H. (1961) Precipitation of silver phosphate from homogenous solution. Analytical Chemistry 33, $873-874$.

Fourel F., Martineau F., Lécuyer C., Kupka H., Lange L., Ojeimi C. and Seed M. (2011) 18O/16O ratio measurements of inorganic and organic materials by elemental analysis-pyrolysis-isotope ratio mass spectrometry continuous-flow techniques. Rapid Communications in Mass Spectrometry 25, 2691-2696.

Fry B., Mersch F. J., Tholke K., Garritt R. and Brand W. (1992) Automated Analysis System for Coupled $\delta^{13}$ C and $\delta^{15} \mathrm{~N}$ Measurements. Analytical Chemistry 64, 288-291.

Grimes V. and Pellegrini M. (2013) A comparison of pretreatment methods for the analysis of phosphate oxygen isotope ratios in bioapatite. Rapid Communications in Mass Spectrometry 27, 375-390.

Henry L. and Wickham H. (2018) purrr: Functional Programming Tools, 2017. 5.

Hillson S. (2005) Teeth., Cambridge.

Hunsinger G. B. and Stern L. A. (2012) Improved accuracy in high-temperature conversion elemental analyzer 
$\delta^{18} \mathrm{O}$ measurements of nitrogen-rich organics. Rapid Communications in Mass Spectrometry 26, 554-562.

Iacumin P., Bocherens H., Mariotti a. and Longinelli A. (1996) Oxygen isotope analyses of co-existing carbonate and phosphate in biogenic apatite: a way to monitor diagenetic alteration of bone phosphate? Earth and Planetary Science Letters 142, 1-6.

Kirsanow K., Makarewicz C. A. and Tuross N. (2008) Stable oxygen $\left(\delta^{18} \mathrm{O}\right)$ and hydrogen $(\delta \mathrm{D})$ isotopes in ovicaprid dentinal collagen record seasonal variation. Journal of Archaeological Science 35, 3159-3167.

Kirsanow K. and Tuross N. (2011) Oxygen and hydrogen isotopes in rodent tissues: Impact of diet, water and ontogeny. Palaeogeography, Palaeoclimatology, Palaeoecology 310, 9-16.

Koch P. L., Tuross N. and Fogel M. L. (1997) The Effects of Sample Treatment and Diagenesis on the Isotopic Integrity of Carbonate in Biogenic Hydroxylapatite. Journal of Archaeological Science 24, 417-429.

Lee-Thorp J. A. and Sealy J. (2008) Beyond documenting diagenesis: The fifth international bone diagenesis workshop. Palaeogeography, Palaeoclimatology, Palaeoecology 266, 129-133.

Lécuyer C. (2004) Oxygen isotope analysis of phosphate. In Handbook of stable isotope analytical techniques: Volume $i$ Elsevier. pp. 482-496.

Lécuyer C., Fourel F., Martineau F., Amiot R., Bernard A., Daux V., Escarguel G. and Morrison J. (2007) High-precision determination of18O/16O ratios of silver phosphate by EA-pyrolysis-IRMS continuous flow technique. Journal of Mass Spectrometry 42, 36-41.

Lécuyer C., Grandjean P., O’Neil J. R., Cappetta H. and Martineau F. (1993) Thermal excursions in the ocean at the Cretaceous-Tertiary boundary (northern Morocco): $\delta^{18} \mathrm{O}$ record of phosphatic fish debris. Palaeogeography, Palaeoclimatology, Palaeoecology 105, 235-243.

Lécuyer C., Grandjean P. and Sheppard S. M. F. (1999) Oxygen isotope exchange between dissolved phosphate and water at temperatures $135 \mathrm{C}$ : inorganic versus biological fractionations. Geochimica et Cosmochimica Acta 63, $855-862$.

Longinelli A. (1984) Oxygen isotopes in mammal bone phosphate: A new tool for paleohydrological and paleoclimatological research? Geochimica et Cosmochimica Acta 48, 385-390.

Longinelli A. and Nuti S. (1973) Oxygen isotope measurements of phosphate from fish teeth and bones. Earth and Planetary Science Letters 20, 337-340.

Luz B., Cormie A. B. and Schwarcz H. P. (1990) Oxygen isotope variations in phosphate of deer bones. Geochimica et Cosmochimica Acta 54, 1723-1728.

Luz B., Kolodny Y. and Horowitz M. (1984) Fractionation of oxygen isotopes between mammalian bone-phosphate and environmental drinking water. Geochimica et Cosmochimica Acta 48, 1689-1693.

Malitson I. H. (1963) A redetermination of some optical properties of calcium fluoride. Applied Optics 2, $1103-1107$.

Matson S. D. and Fox D. L. (2008) Can oxygen isotopes from turtle bones be used to reconstruct paleoclimates? 
Palaios 23, 24-34.

Mine A., Waldeck A., Olack G., Hoerner M., Alex S. and Colman A. (2017) Microprecipitation and $\delta^{18} \mathrm{O}$ analysis of phosphate for paleoclimate and biogeochemistry research. Chemical Geology 460, 1-14.

Müller K. and Wickham H. (2018) tibble: Simple Data Frames. R package version 1.4.2.

O'Neil J. R., Roe L., Reinhard E. and Blake R. (1994) A rapid and precise method of oxygen isotope analysis of biogenic phosphate. Israel Journal of Earth Sciences 43, 203-212.

Passey B. H., Robinson T. F., Ayliffe L. K., Cerling T. E., Sponheimer M., Dearing M. D., Roeder B. L. and Ehleringer J. R. (2005) Carbon isotope fractionation between diet, breath CO2, and bioapatite in different mammals. Journal of Archaeological Science 32, 1459-1470.

Pederzani S. and Britton K. (2019) Oxygen isotopes in bioarchaeology: Principles and applications, challenges and opportunities. Earth-Science Reviews 188, 77-107.

Pellegrini M., Donahue R. E., Chenery C. A., Evans J. A., Lee-Thorp J. A., Montgomery J. and Mussi M. (2008) Faunal migration in late-glacial central Italy: implications for human resource exploitation. Rapid communications in mass spectrometry : RCM 22, 1714-1726.

Pellegrini M. and Snoeck C. (2016) Comparing bioapatite carbonate pre-treatments for isotopic measurements: Part 2 - Impact on carbon and oxygen isotope compositions. Chemical Geology 420, 88-96.

Pollard A. M. (2011) Isotopes and impact: a cautionary tale. Antiquity 85, 631-638.

Pucéat E., Joachimski M. M., Bouilloux A., Monna F., Bonin A., Motreuil S., Morinière P., Hénard S., Mourin J., Dera G. and Quesne D. (2010) Revised phosphate-water fractionation equation reassessing paleotemperatures derived from biogenic apatite. Earth and Planetary Science Letters 298, 135-142.

Qi H., Coplen T. B. and Wassenaar L. I. (2011) Improved online $\delta^{18} \mathrm{O}$ measurements of nitrogen- and sulfurbearing organic materials and a proposed analytical protocol. Rapid Communications in Mass Spectrometry 25, 2049-2058.

Quade J., Cerling T. E., Barry J. C., Morgan M. E., Pilbeam D. R., Chivas A. R., Lee-Thorp J. A. and Merwe N. J. van der (1992) A 16-Ma record of paleodiet using carbon and oxygen isotopes in fossil teeth from Pakistan. Chemical Geology 94, 183-192.

R Core Team (2017) R: A Language and Environment for Statistical Computing.

Shabaga B. M., Gough H., Fayek M. and Hoppa R. D. (2018) A simplified silver phosphate extraction method for oxygen isotope analysis of bioapatite. Rapid Communications in Mass Spectrometry 32, 1237-1242.

Slowikowski K. (2018) ggrepel: Automatically Position Non-Overlapping Text Labels with'ggplot2'.

Snoeck C. and Pellegrini M. (2015) Comparing bioapatite carbonate pre-treatments for isotopic measurements: Part 1-Impact on structure and chemical composition. Chemical Geology 417, 349-403.

Stephan E. (2000) Oxygen Isotope Analysis of Animal Bone Phosphate: Method Refinement, Influence of Consolidants, and Reconstruction of Palaeotemperatures for Holocene Sites. Journal of Archaeological Science 27, 
523-535.

Tuross N., Warinner C., Kirsanow K. and Kester C. (2008) Organic oxygen and hydrogen isotopes in a porcine controlled dietary study. Rapid communications in mass spectrometry 22, 1741-1745.

Tütken T., Vennemann T. W., Janz H. and Heizmann E. P. J. (2006) Palaeoenvironment and palaeoclimate of the Middle Miocene lake in the Steinheim basin, SW Germany: A reconstruction from C, O, and Sr isotopes of fossil remains. Palaeogeography, Palaeoclimatology, Palaeoecology 241, 457-491.

von Holstein I. C. C., Von Tersch M., Coutu A. N., Penkman K. E. H., Makarewicz C. A. and Collins M. J. (2018) Collagen proteins exchange oxygen with demineralisation and gelatinisation reagents and also with atmospheric moisture. Rapid Communications in Mass Spectrometry 32, 523-534.

Walsh W. R., Walton M., Bruce W., Yu Y., Gillies R. M. and Svehla M. (2003) Cell Structure and Biology of Bone and Cartilage. In Handbook of histology methods for bone and cartilage Humana Press, Totowa, NJ. pp. 35-58.

Warinner C. and Tuross N. (2010) Brief communication: Tissue isotopic enrichment associated with growth depression in a pig: Implications for archaeology and ecology. American Journal of Physical Anthropology 141, 486-493.

Wickham H. (2018) Forcats: Tools for working with categorical variables (factors).

Wickham H. (2016) ggplot2: Elegant Graphics for Data Analysis., Springer New York.

Wickham H. (2018a) Stringr: Simple, consistent wrappers for common string operations, r package version 1.3.1.

Wickham H. (2018b) Tidyverse: Easily Install and Load the'Tidyverse'. 2017. R package version 1.2. 1.

Wickham H., Francois R., Henry L. and Müller K. (2018) dplyr: A Grammar of Data Manipulation. R package version 0.7.7.

Wickham H. and Henry L. (2018) tidyr: Easily Tidy Data with spread () and gather () Functions. R package version 0.8.2. $R$ package version 0.63 .

Wickham H., Hester J., Francois R., Jylänki J. and Jørgensen M. (2017) readr: read rectangular text data. R package version 1.1. 1.

Wiedemann-Bidlack F., Colman A. S. and Fogel M. L. (2008) Phosphate oxygen isotope analysis on microsamples of bioapatite: removal of organuc contamination and minimzation of sample size. Rapid communications in mass spectrometry 22, 1807-1816.

Williams R. A. D. and Elliott J. C. (1989) Basic and applied dental biochemistry., Churchill Livingstone, Edinburgh; New York.

Wright E. K. and Hoering T. C. (1989) Separation and purification of phosphates for oxygen isotope analysis. Annual Report of the Director, Geophysical Laboratory, Carnegie Institute 2150, 137-141.

Xie Y. (2016) Bookdown: Authoring Books and Technical Documents with R Markdown., Chapman; Hall/CRC. Xie Y. (2014) knitr: a comprehensive tool for reproducible research in R. Implement Reprod Res 1, 20.

Zazzo A., Lécuyer C., Sheppard S. M. F., Grandjean P. and Mariotti A. (2004) Diagenesis and the reconstruction 
843 of paleoenvironments: A method to restore original $\delta^{18} \mathrm{O}$ values of carbonate and phosphate from fossil tooth enamel. ${ }_{844}$ Geochimica et Cosmochimica Acta 68, 2245-2258.

Zhu H. (2018) KableExtra: Construct complex table with'kable'and pipe syntax. R package version 0.9.0. URL 846 https://CRAN. R-project. org/package=kableExtra, r package version 0.9. 0. 